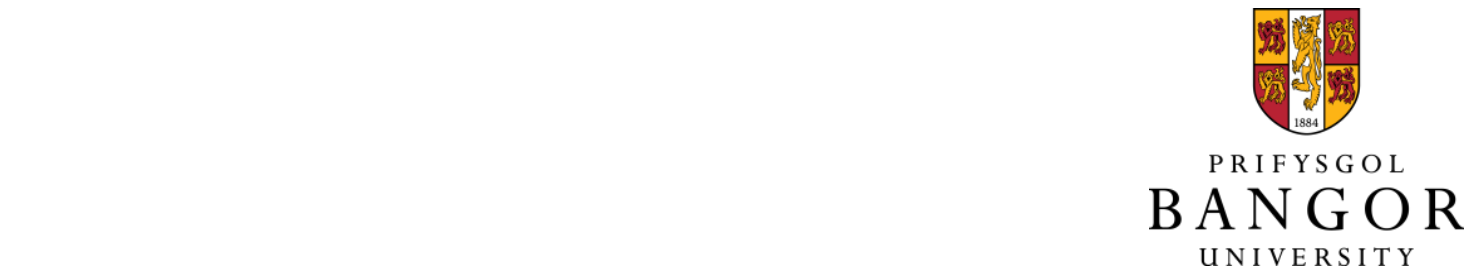

Asymmetric competitive effects during species range expansion: an experimental assessment of interaction strength between 'equivalent' grazer species in their range overlap.

Aguilera, Moises A.; Valdivia, Nelson; Jenkins, Stuart; Navarette, Sergio A.; Broitman, Bernardo

Journal of Animal Ecology

DOI:

$10.1111 / 1365-2656.12917$

Published: 01/02/2019

Peer reviewed version

Cyswllt i'r cyhoeddiad / Link to publication

Dyfyniad o'r fersiwn a gyhoeddwyd / Citation for published version (APA):

Aguilera, M. A., Valdivia, N., Jenkins, S., Navarette, S. A., \& Broitman, B. (2019). Asymmetric competitive effects during species range expansion: an experimental assessment of interaction strength between 'equivalent' grazer species in their range overlap. Journal of Animal Ecology, 88(2), 277-289. https://doi.org/10.1111/1365-2656.12917

Hawliau Cyffredinol / General rights

Copyright and moral rights for the publications made accessible in the public portal are retained by the authors and/or other copyright owners and it is a condition of accessing publications that users recognise and abide by the legal requirements associated with these rights.

- Users may download and print one copy of any publication from the public portal for the purpose of private study or research.

- You may not further distribute the material or use it for any profit-making activity or commercial gain

- You may freely distribute the URL identifying the publication in the public portal ?

Take down policy

If you believe that this document breaches copyright please contact us providing details, and we will remove access to the work immediately and investigate your claim. 

Asymmetric competitive effects during species range expansion: an experimental assessment of interaction strength between 'equivalent' grazer species in their range overlap

Moisés A. Aguilera ${ }^{1,2}$, Nelson Valdivia ${ }^{3,4}$, Stuart Jenkins ${ }^{6}$ Sergio A. Navarrete $^{5}$, Bernardo

Broitman $^{2}$

${ }^{1}$ Departamento de Biología Marina, Facultad de Ciencias del Mar, Universidad Católica del Norte, Larrondo 1281, Coquimbo, Chile ${ }^{2}$ Centro de Estudios Avanzados en Zonas Áridas (CEAZA) Ossandón 877, Coquimbo, Chile. Sustainability, Pontificia Universidad Católica de Chile, Casilla 114-D, Santiago, Chile. 


\section{Abstract}

23 1. Biotic interactions are central to the development of theory and concepts in community

24 ecology; experimental evidence has shown their strong effects on patterns of population

25 and community organization and dynamics over local spatial scales. The role of

26 competition in determining range limits and preventing invasions at biogeographic scales is

27 more controversial, partly because of the complexity of processes involved in species

28 colonization of novel habitats and the difficulties in performing appropriate manipulations

29 and controls.

30 2. We examined experimentally whether competition is likely to affect poleward range

31 expansion hindering or facilitating the establishment of the limpet Scurria viridula along

32 the southeastern Pacific rocky shore $\left(30^{\circ} \mathrm{S}\right.$, Chile $)$ in the region occupied by the congeneric

33 S. zebrina. We also assessed whether competition with the "invader" or range expanding

34 species could reduce individual performance of the 'native' S. zebrina and depress local

35 populations

36 3. Geographic field surveys were conducted to characterize the abundance and identity of

37 limpets along the south-eastern Pacific coast from $18^{\circ} \mathrm{S}$ to $41^{\circ} \mathrm{S}$, and the micro-scale (few

$38 \mathrm{~cm}$ ) spatial distribution across the range overlap of the two species. Field-based

39 competition experiments were conducted at the southern leading edge of the range of $S$.

40 viridula $\left(33^{\circ} \mathrm{S}\right)$ and at the northern limit of S. zebrina $\left(30^{\circ} \mathrm{S}\right)$.

41 4. Field surveys showed poleward range expansion of $S$. viridula of ca. $210 \mathrm{~km}$ since year

42 2000, with an expansion rate of $13.1 \mathrm{~km}$ year $^{-1}$. No range shift was detected for S. zebrina.

43 The resident $S$. zebrina had significant negative effects on the growth rate of the invading 
44 juvenile S. viridula, while no effect of the latter was found on S. zebrina. Spatial

45 segregation between species was found at the scale of $\mathrm{cms}$.

46 5. Our results provide novel evidence of an asymmetric competitive effect of a resident

47 species on an invader, which may hamper further range expansion. No negative effect of

48 the invader on the resident species was detected. This study highlights the complexities of

49 evaluating the role of species interactions in setting range limits of species, but showed how

50 interspecific competition might slow the advance of an invader by reducing individual

51 performance and overall population size at the advancing front.

52

53

54

55

56

57

58

59

60

61

62

63

64

65

66

67

68

69

\section{KEYWORDS}

Field experiments, grazers, range overlap, range shift, Pacific Ocean, transitional zone.

5

6

\section{7} 8 9

0

1

2

3

4

5

6

7

8

6




\section{1 | INTRODUCTION}

72 The range limits of species are influenced by changes in environmental conditions,

73 suitable habitat scarcity and dispersal limitation (Brown, Stevens, \& Kaufman, 1996; Case,

74 Holt, Mcpeek, \& Keitt, 2005; Holt \& Keitt, 2005; Vermeij, 2005). However, beyond large-

75 scale environmental regulation, increasing theoretical and empirical evidence hints that

76 biotic interactions can determine the distribution boundaries of species (e.g. Cunningham et

77 al., 2009; Firth et al., 2009; Soberón, 2010; Araújo \& Rozenfeld, 2014; Godsoe et al.,

78 2017). Theory predicts that in geographic contact zones competitive interactions can leave

79 a strong impact on species distribution at regional scales and can lead to the formation of

80 stable geographic range edges (Araújo \& Luoto, 2007; Godsoe, Murray, \& Plank, 2015;

81 Phillips, 2012). However, manipulative field studies determining how the strength of

82 competition influences the dynamics of species range limits are still scarce (but see

83 Cunningham et al., 2009).

84 The performance of species at the limit of their geographic range, where they overlap the

85 distribution of other potentially competing species with similar resource requirements, may

86 be critical in determining the role of competition in establishing the distribution and the

87 probability of range expansion (Godsoe et al., 2015 Phillips, 2012). Range overlap can also

88 drive ecological niche divergence over time (Pigot \& Tobias, 2013). Relevant population

89 and individual properties such as density, individual size and fecundity can decrease from

90 central to edge subpopulations due to varying abiotic environmental effects on individual

91 physiology (e.g. Brown, 1984; Sagarin \& Gaines, 2002; Gilman, 2006; Rivadeneira et al.,

92 2010). This core-edge adaptive pattern could lead to a concomitant decrease in competitive 
93 ability from central to edge locations, with important implications for competition at the

94 range edges of overlapping populations. For example, competitive exclusion by local

95 species has been proposed to prevent the success of an invading species (Case \& Taper,

96 2000; Godsoe \& Harmon, 2012), halting the range expansion of the latter. Therefore,

97 determining the differences in competitive ability between species overlapping at their

98 respective range-edges will improve our understanding of the influence of ecological

99 interactions on species' range variability.

100 Coastal biogeographic boundaries provide a model system to assess the influence of 101 competition on the geographic distribution of species (Firth et al., 2009). In the

102 Southeastern Pacific (SE) shore, a well-known transition zone (i.e. subtropical-temperate)

103 extending between $30^{\circ} \mathrm{S}$ and $41^{\circ} \mathrm{S}$ concentrates the polar or equatorial range edge of at least

1047 intertidal species (Camus, 2001; Broitman et al., 2011). Clear signs of range shifts (i.e.

105 contraction or expansion) have been detected here for six intertidal grazer species (e.g.

106 Rivadeneira \& Fernández, 2005). Some of these recently shifted populations have increased

107 species co-occurrences, with the potential for pronounced effects on the fitness of

108 previously established ecological and phylogenetically equivalent species.

109 The scurrinid limpets Scurria viridula and S. zebrina co-occur across $\sim 300 \mathrm{~km}$ of

110 coastline within the transition zone in the SE Pacific shore. These limpets share several

111 characteristics in terms of resource requirements and habitat use. These species are the most

112 recent species of the Scurria clade (Espoz, Lindberg, Castilla, \& Simison, 2004) and have a

113 similar generalist diet (Camus, Daroch, \& Opazo, 2008). They are distributed across similar

114 intertidal habitats (mid to high levels) characterized by flat, inclined and wave-exposed

115 rocky areas, potentially leading to strong competition between populations (e.g. via 
116 interference or exploitation). The population of $S$. viridula has expanded poleward during

117 the last two decades, from $32.3^{\circ} \mathrm{S}$ to ca. $33^{\circ} \mathrm{S}$ and hence into the range of S. zebrina

118 (Aguilera et al., 2013) (see dotted red line in Fig. 1). This poleward range shift prompts the

119 question as to whether competition with the "native" S. zebrina can prevent or limit the

120 establishment of the "invasive" S. viridula. Leading edge populations are usually composed

121 of juveniles, which might reduce their competitive abilities against native competitors (e.g.

122 Collisella; Gilman, 2006).

Here we take advantage of the current poleward range shift of the subtropical limpet $S$.

124 viridula to examine experimentally two tightly connected questions: Does $S$. zebrina affect

125 negatively the abundance of the leading-edge populations of $S$. viridula? And inversely,

126 does competition with $S$. viridula reduce the ability of populations of the native species $S$.

127 zebrina to persist in time? We hypothesize that, given the high similarity of traits in $S$.

128 viridula and S. zebrina, but their reduced local performance (Navarrete, Wieters, Broitman,

129 \& Castilla, 2005) (because of their range edge position, Broitman, Aguilera, Lagos, \&

130 Lardies, 2018), each species would have reduced competitive ability in its respective range

131 edge. We predict that (1) for the native species, S. zebrina, growth and survival should be

132 lower in the presence of adult or juvenile $S$. viridula (blue arrow in Fig.1) and (2) for the

133 leading edge species. S. viridula, growth and survival of juveniles should be lower in the

134 presence of either adult or juvenile S. zebrina (red arrow in Fig. 1). In addition to

135 examining direct competitive effects, we also assessed small-scale patterns of segregation

136 or aggregation in $S$. viridula and $S$. zebrina. Such spatial patterns can change the effective

137 strength of competitive interactions between species (Bolker \& Pacala, 1997; Dixon, 2009).

138 It is expected that small scale segregation (i.e. larger individual-to-individual patterns) 
139 between the Scurria species may allow a few individuals of S. viridula to grow to adult size

140 in the leading edge, and thus may play some role facilitating local coexistence.

141 Consequently, small scale $(\mathrm{cm})$ interspecific spatial segregation during resting and foraging

142 (i.e. spatial niche segregation; Aguilera et al., 2013) might result in lower heterospecific

143 deleterious effects. Therefore, we examined the distribution of heterospecific nearest

144 neighbor distances and local occurrences at the range overlap of these Scurria species.

145 Given that suitable habitat for settlement is one of the main factors determining species

146 distribution and range shift, especially in intertidal species with larval development (Case et

147 al., 2005; Fenberg \& Rivadeneira, 2011), we also explore suitable habitat availability for

148 settlement of the expanding S. viridula at its leading edge.

\section{2 | MATERIALS AND METHODS}

151

2.1 Study system, range shift and geographic abundance patterns of Scurria.

153 The coastline of the study region is composed mostly of continuous, wave-exposed rocky

154 shores, with only $20 \%$ interspersed sandy beaches. The northern limit of the range overlap $155\left(30^{\circ} \mathrm{S}\right)$ between Scurria viridula and Scurria zebrina is characterized by the presence of a 156 large coastal headland, which is recognized as the strongest upwelling area in north-central 157 Chile (Aguirre, Pizarro, Strub, Garreaud, \& Barth, 2012).

158 Previous comparison of abundance and occurrence data over the period 1998-2008

159 (Aguilera, Valdivia, \& Broitman, 2013) and early records suggests that the southern limit of 160 S. viridula has shifted from $29^{\circ} 55^{\prime}$ 'S in 1962 to $31^{\circ} 51^{\prime}$ 'S in 2001 (Rivadeneira \& Fernández, 
1612005 ) to $33^{\circ} 30^{\prime} S$ in our study (see below). Recent field surveys (2010-2011) found

162 juvenile $S$. viridula individuals at $33^{\circ} 30^{\prime} S$ constituting a new leading edge of this species

163 (Aguilera et al., 2013). Thus a continuous poleward range expansion has been observed

164 over recent decades.

165 To estimate the rate of recent range expansion of S. viridula, we recorded the

166 abundance of both $S$. viridula and $S$. zebrina at 25 sites located along the coast of Chile

167 from $18^{\circ} \mathrm{S}$ to $41^{\circ} \mathrm{S}$ (see Fig.S1 in Supporting Information) over the period January 2013 to

168 March 2016. This was done by considering a minimum of 10, $30 \times 30 \mathrm{~cm}$ quadrats (see

169 Table S1 in Supporting Information) placed in $\sim 5$ to $10 \mathrm{~m}$ alongshore transects in the mid-

170 high intertidal zone (1.5 to $2.0 \mathrm{~m}$ above MLWL) of each site. Transects were conducted

171 along wave-exposed rocky platforms (ranging from 24 to $\sim 500 \mathrm{~m}^{2}$ ) with $45-80^{\circ}$ slope,

172 where most large- and medium-sized Scurria individuals can be found. The size of rocky

173 platform ranged from 20 to $120 \mathrm{~m}^{2}$ (see further details in Table S1 in Supporting

174 Information). A total of 2054 quadrats were sampled, and in addition each platform was

175 inspected in full to detect the presence or corroborate the absence of $S$. viridula or $S$.

$176 \quad z e b r i n a$ at each site.

177 Surveys encompassed the entire geographic range of S. zebrina (from $41^{\circ} \mathrm{S}$ to $30^{\circ} \mathrm{S}$ ) and 178 about $80 \%$ of the geographic range of $S$. viridula, between $18^{\circ} \mathrm{S}$ and $33^{\circ} \mathrm{S}$, representing 179 about $1300 \mathrm{~km}$ of coastline. Scurria viridula has been found as far north as $12^{\circ} \mathrm{S}$ in Peru 180 (Espoz et al., 2004). Sampling sites were arbitrarily selected based on accessibility, but 181 were well within the latitudinal range considered by previous authors (Espoz et al., 2004;

182 Rivadeneira \& Fernández, 2005). Most sites, except six sites from $37^{\circ} \mathrm{S}$ to $41^{\circ} \mathrm{S}$, were 183 sampled twice per year, and six sites located between $28^{\circ} \mathrm{S}$ and $33^{\circ} \mathrm{S}$ were sampled 
184

185

186

187

188

exceptionally three to four times per year. This sampling gave us information on temporal changes in abundance and the extension of the range overlap of these Scurria species. Thus, we estimated the expansion/contraction of Scurria species based on information of their previous northern $(S$. zebrina $)$ and southern $(S$. viridula $)$ range edge along the coast (Rivadeneira \& Fernández 2005; Aguilera et al., 2013). In addition, we assessed the spatial variation in body size structure of both species using direct measurements of shell length in a subsample of 14 sites, six of them concentrated within the range overlap. We measured with a caliper ( $0.2 \mathrm{~cm}$ precision) the shell length of all individuals encountered in $15-20 \mathrm{~m}$ long and $2.0 \mathrm{~m}$ wide transects located in the mid-high intertidal level. A total of 6841 individuals were measured. Differences in shell length between species and among the six sites sampled in the range overlap were analyzed by two-way ANOVA. For this analysis, we use shell length of 3748 individuals (i.e. 312 individual per species and per site). In the case of significant effects, post-hoc Tukey's HSD test was used to compare differences in sites, species and sites by species effects. Analyses were made using the library 'vegan' in the R-environment (R Development Core Team, R, 2017)

\subsection{Local interspecific distribution patterns}

To evaluate the potential micro-scale segregation of the Scurria species in the field, we quantified the interspecific spatial co-occurrences at small scales (few centimeters) of the Scurria species using two complementary techniques; abundance correlation in quadrats and individual nearest neighbor distances (Fortin \& Dale, 2005). Quadrat-based sampling was conducted at 4 sites in the range overlap (Guanaqueros, Limarí, Punta Talca and Huentelauquén) and at one site at the leading edge of S. viridula (Quintay; see arrows in 
207

208

209

210

211

212

213

214

215

216

217

218

219

220

221

222

223

224 frequency of heterospecific nearest neighbor distances across sites by constructing

225

226 227 environment (R Development Core Team, R, 2017)

Fig. 1). Scurria spatial association at the $900-\mathrm{cm} 2$ scale was determined by estimating the lag-0 Pearson correlation (r) between focal limpet species density across quadrats at each locality, which is recommended for data with autocorrelated structure, and is appropriated to describe and test the spatial aggregation or dispersion of species (Fortin \& Dale, 2005). Significance was calculated by a t-test corrected for the effective degrees of freedom based on lag-1 autocorrelation estimates of Moran's I (Dutilleul, 1993). At the same localities, finer spatial distribution, i.e. individual-to-individual distances, was characterized by measuring nearest neighbor distances between conspecific and heterospecific individuals (from $S$. viridula to $S$. zebrina individuals and vice versa). The shape of the nearest neighbor distance distribution commonly captures processes operating between individuals scale (e.g. behavior) and reflects positive (aggregation) and negative (segregation) associations (Fortin \& Dale, 2005). At each locality we selected four $4 \times 4 \mathrm{~m}$ areas where we estimated all conspecific and heterospecific nearest neighbor distances starting with a selected individual positioned in the middle of the sampling area. To reduce nonindependence of measured heterospecific NN distances, the distances from S. viridula to $S$. zebrina and from S. zebrina to S. viridula were measured in different areas. More than 200 individual-to-individual distances were measured at each locality. We analyzed the contingency tables. Independence was tested with a log-linear model using likelihood Ratio and Pearson's Chi-square statistic $(\alpha=0.05)$ implemented in the 'MASS' library of the R- 
We conducted field experiments at two sites to test the effects of competition on growth

231 and survival of $S$. viridula and S. zebrina at their respective range edges. One site, Punta

232 Talca $\left(30^{\circ} \mathrm{S}\right)$, corresponded to the historic range overlap of both species and to the trailing

233 edge of $S$. zebrina. The other site, Las Cruces ( $\left.33^{\circ} 30^{\prime} S\right)$, is at the leading edge of $S$.

234 viridula. The experiments were conducted at each site on $24,35 \times 35 \mathrm{~cm}$ natural rock plots

235 with a slope ranging from $50^{\circ}$ to $65^{\circ}$ in the mid-high intertidal zone. Experimental studies

236 in Europe (Boaventura, Cancela, Fonseca, \& Hawkins, 2003), South Africa (Lasiak \&

237 White, 1993) and Australia (Marshall \& Keough, 1994) have shown that competition in

238 intertidal limpets is more intense between size classes. Since small size classes dominated

239 the size distribution of both Scurria species at their range edges (Aguilera et al., 2013); we

240 focused on interactions among these smaller size classes, and between these and larger,

241 adult individuals. Thus, we examined the effect of $S$. viridula on S. zebrina juvenile

242 individuals at the historic range overlap $\left(30^{\circ} \mathrm{S}\right)$, separating between intraspecific, intra- and

243 inter-size class effects within $S$. zebrina and the interspecific effect of $S$. viridula juveniles

244 and adults on S. zebrina (Fig.1 and see Appendix 2 for details). In a separate experiment

245 with the same general design (Fig. 1), we examined the effect of S. zebrina on the invading

246 S. viridula at the leading edge of the latter species ( $\left.33^{\circ} 30^{\prime} S\right)$. This experiment also

247 separated between intraspecific, intra- and inter-size class effects within $S$. viridula from

248 interspecific effects of juveniles and adults $S$. zebrina on juveniles of $S$. viridula (Fig.1, see

249 Appendix 2 for details of the experimental design and field deployment). Intraspecific

250 effects were investigated in both sites at natural and high densities (two or four individuals

251 per plot, respectively; see Table 1 and Fig. 1), and interspecific effects were examined

252 using natural densities of each species (two individuals of each species). The design yielded

253 therefore six treatments in each site; Historic range overlap (HRO): 1) 2 S. zebrina 
254 juveniles; 2) 4 S. zebrina juveniles; 3) 2 S. zebrina adults; 4) 2 S. zebrina juveniles plus $2 S$.

255 zebrina adults; 5) 2 S. zebrina juveniles plus 2 S. viridula juveniles; and 6) 2 S. zebrina

256 juveniles plus 2 S. virdula adults. Leading edge (LE): 1) 2 S. viridula juveniles; 2) $4 S$.

257 viridula juveniles; 3) 2 S. viridula adults; 4) 2 S. viridula juveniles plus 2 S. viridula adults;

258 5) $2 S$. viridula juveniles plus 2 S. zebrina juveniles; and 6) $2 S$. viridula juveniles plus $2 S$.

259 zebrina adults (see scheme in Fig. 1). Scurria individuals were enclosed in experimental

260 areas $(35 \times 35 \mathrm{~cm})$ using stainless steel mesh cages $(8 \mathrm{~cm}$ high, $10 \mathrm{~mm}$ mesh size $)$ fastened

261 to the rock with stainless steel screws (see Appendix 2 for details). Treatments were

262 randomly allocated to experimental areas and replicated four times. The experiments were

263 initiated on June 25, 2014 at the Punta Talca and on June 29, 2014 at Las Cruces -both

264 experiments ended on December 5, 2014.

At the beginning and at the end of the experiment we measured shell length and weighed

266 all animals. We calculated growth rates of each limpet as $G R=\frac{(W t-W o)}{t}$, where Wo $=$ wet

267 weight at the start, $\mathrm{Wt}=$ the wet weight at the end, and $\mathrm{t}=$ elapsed time in days. All

268 observations and manipulations were conducted during diurnal low-tide hours.

The predictions that growth of S. zebrina at the edge corresponding to the historic range overlap, will be negatively affected by $S$. viridula (Prediction 1), and that growth of $S$.

271 viridula at its leading edge will be negatively affected by the S. zebrina (Prediction 2) were

272 tested by analyzing separately the results from two experimental sites. For each site, we 273 used nested ANOVAs for each species and dependent variables. Data were log-transformed 274 to improve variance homogeneity and normality after inspection of residuals. Treatment 275 was considered a fixed factor with six treatments from the two experimental sites: three 276 intraspecific treatments (intra-class interactions: juvenile-juvenile, adult-adult; inter-class: 
277 juvenile-adult interaction) with two densities for juvenile-juvenile intra-class treatment

278 (two and four individuals), and two interspecific treatments (juveniles of each species and

279 adult-juvenile). Plots (experimental areas) were considered independent replicates.-

280 Observations on the individuals within plots represented the sub-replication of each plot.

281 When significant effects where found, the post-hoc Tukey HSD test was used to compare

282 the conspecific treatments against each other (intraspecific effects), and to mixed-species

283 treatment (interspecific effects). All analyses were made using the 'MASS' library and

284 'vegan' of the R-environment (R Development Core Team, R, 2017).

285

286

287

288

289

290

$291 \frac{\left(R H i_{k}-R N i_{k}\right)}{\left(N H i_{k}-N N i_{k}\right)}$, where $R N i_{k}$ is the per capita response variable (e.g. growth rate) of species $i$ of

292 size class $k$ (juvenile or adult) in the average or "natural" density treatment, $R H i_{k}$ is the per

293 capita response measured in the high density treatment, and $N N i_{k}$ and $N H i_{k}$ are the numbers

294 of individuals in the natural and high density treatments, respectively. Thus for each

295 location we estimated three intraspecific effects; juvenile on juvenile $\left(I S i_{j j}\right)$, adult on

296 juvenile $\left(I S i_{a j}\right)$, and juvenile on adult $\left(I S i_{j a}\right)$. For interspecific effects, we considered a total

297 per capita interspecific effect (Total_ISij) of species j on species $i$ calculated as:

298 Total_IS $i j_{k}=\frac{\left(R M i j_{k}-R N i_{k}\right)}{N j_{k}}$, where $R M i j_{k}$ is the per capita response of species $i$ measured in 
299 the mixed species enclosures with species $j$ of size class $k$, and $N j_{k}$ is the number of 300 individuals of species $j$ of class $k$ present in those enclosures. In order to include the effect

301 of species identity, and to separate the effect of individuals of the same species but of 302 different size-class, we obtained an estimate of "pure" interspecific per capita effect $I S i_{k}$ 303 as; $I S i j_{k}=$ Total_ISij $j_{k}-I S i_{k}$ (see Appendix S3 for further details).

\subsubsection{Scurria microspatial distribution in experimental cages}

306 Each two weeks per month, we estimate con- and heterospecific nearest neighbor-distances 307 in the experimental enclosures in field experiments. We estimated the probability density 308 function (PDF) for conspecific and heterospecific nearest neighbor distance distribution in 309 each experimental plot. Thus, considering that nearest neighbor distances are continuous 310 random variables, the PDF (i.e. kernel density plot) was estimated as the ratio of individual

311 nearest neighbor distances values versus the average total. This analyses provide a useful 312 way to explore individual (con-and heterospecific) segregation or aggregation (Manly, 313 1997). Density plots were performed with the package 'sm' implemented in $R$ ( $R$ 314 Development Core Team, 2017)

317 To provide information on habitat availability, which can limit geographic distribution 318 and range shifts of limpet species (Fenberg \& Rivadeneira, 2011), we examined the 319 proportion of habitats available/unavailable for $S$. viridula settlement across its leading 
edge. Analyses were conducted by tracing contours of the coast (from $32^{\circ} \mathrm{S}$ to $33.3^{\circ} \mathrm{S}$ ) in Google Earth Pro ${ }^{\circledR}$ at a constant elevation $(500 \mathrm{~m})$, determining the length of unsuitable (sandy beach) and suitable (rocky shore) habitats present across the range following previous studies (e.g. Fenberg \& Rivadeneira, 2011). Coastal artificial structure length present on either rocky or sandy beaches were also considered in the analyses.

\section{3 | RESULTS}

\subsection{Range shift and geographic patterns of abundance of $S$. viridula and $S$.} zebrina

Field abundance surveys conducted along the coast of Chile from $18^{\circ} \mathrm{S}$ to $41^{\circ} \mathrm{S}$ showed parapatric geographic distributions of the Scurria species, with an overlap of about $375 \mathrm{~km}$ in central Chile (Fig. 2 and Fig. S1 in Supporting Information). Scurria viridula showed an poleward range expansion into the range of $S$. zebrina from $32^{\circ} 31^{\prime} \mathrm{S}$ to $33^{\circ} 33^{\prime} \mathrm{S}$ in central Chile (see dotted blue lines in Fig. 2); this corresponds to a range shift of ca. $210 \mathrm{~km}$ (linear length estimates) in 16 years (2000 to 2016), representing a poleward expansion rate of $S$. viridula of about $13.1 \mathrm{~km}$ year $^{-1}$. The mean density of $S$. viridula at the historic range overlap was 0.658 indiv. $\times 900 \mathrm{~cm}^{-2}( \pm 0.062)$, while at the leading edge it was 0.153 indiv. $\times$ $900 \mathrm{~cm}^{-2}( \pm 0.0234)$, showing reduced population density. Mean density for S. zebrina was higher at the leading edge of $S$. viridula (2.138 indiv. $\left.\times 900 \mathrm{~cm}^{-2} \pm 0.169\right)$ compared to the historic range overlap (1.035 indiv. $\left.\times 900 \mathrm{~cm}^{-2} \pm 0.116\right)$ which correspond to its northern range limit. 
344 Shell size of the Scurria species was variable across the historic range overlap (HRO),

345 showing a significant site $\times$ species interaction effect (two-way ANOVA; $\mathrm{F}_{5,3735}=4.581 ; \mathrm{P}=$

346 0.00036). The recently established population of $S$. viridula at the leading edge (located

347 from $33.11^{\circ}$ to $33.33^{\circ} \mathrm{S}$ ) had comparable individual shell size to other range edge

348 populations (see Fig. S2 in Supporting Information). The more equatorward population of

349 S. viridula, at $18^{\circ} \mathrm{S}$ showed a median shell size of $25 \mathrm{~mm}$, slightly less than the

350 southernmost population at $33.33^{\circ} \mathrm{S}$, which had a median value of $32 \mathrm{~mm}$ (Fig. S2). The

351 shell size of S. zebrina was different from that found for S. viridula at Punta Talca at the

352 historic range overlap (Tukey HSD test; diff $=-0.556 ; \mathrm{P}<0.0001$ ), but median values for

353 adult limpets were 29 and $31 \mathrm{~mm}$, respectively (Fig. S2). Significant differences were

354 found between the species at the leading edge of $S$. viridula at Las Cruces (Tukey HSD test;

355 diff $=-0.619 ; \mathrm{P}=0.00002$ ), but not at Pelancura located in the same range (Tukey HSD

356 test; diff $=-0.0596 ; \mathrm{P}=0.998)$.

$358 \quad 3.2$ Local interspecific distribution patterns

360 Interspecific abundance distribution patterns estimated for quadrats $\left(900 \mathrm{~cm}^{2}\right)$ at the historic

361 range overlap showed a positive, but low, significant correlation $(\mathrm{r}=+0.0223)$ at only one

362 site (Huentelauquén, $31.38^{\circ} \mathrm{S}$; see Table S2 in Supporting Information). A negative, but

363 not statistically significant, value $(\mathrm{r}=-0.0741)$ was observed at the leading edge of $S$.

364 viridula (Quintay, $33.11^{\circ} \mathrm{S}$; see Table S2, Supporting Information) suggesting that the

365 pattern of individual heterospecific segregation was not strong enough to be detectable

366 among quadrats. 
367

368

369

370

371

372

373

374

375

376 377 and $15 \mathrm{~cm}$; Fig. S3).
378

379

We determined 813 heterospecific individual nearest neighbor distances $(S$. viridula to $S$. zebrina) in the field across the historic range overlap, and at the leading edge of $S$. viridula.

Overall nearest neighbor median distance between the Scurria species was $14.5 \mathrm{~cm}$ across the range considered (see Fig. S3 in Supporting Information); about 300 individuals (36.9\%) showed distances between 0 and $10 \mathrm{~cm}$. A log linear model showed nonindependence of nearest neighbor distances across sites (Likelihood Ratio $=419, \mathrm{P}=$ 0.0125), suggesting individuals of the same species are more likely to cluster than heterospecifics in the sampling sites. This was reflected in the slightly higher distances between heterospecifics at the leading edge of $S$. viridula (median distances between 17.2 $\mathrm{cm}$ and $19.7 \mathrm{~cm}$ ), compared to sites located further north (median distances between 14.3

\subsection{Competition experiments at range edges of S. viridula and S. zebrina}

At the end of the field experiments (200 days) in the historic range overlap, no differences were observed in S. zebrina individual growth rate (i.e. wet weight) in the intraspecific treatments (Fig. 3a and b, Table 2). No significant change was found in the growth rate of juvenile $S$. zebrina enclosed with juvenile or adult $S$. viridula at the historic range overlap or the leading edge (Fig. 3a, Table 2). Juvenile $S$. viridula growth rate was significantly lower in the presence of adult $S$. zebrina at the leading edge (SVj+SZa; Fig. 3b, Table 2) in contrast to the high growth achieved when combined with adults of the same species $(\mathrm{SVj}+\mathrm{SVa}$ ) which was $\sim 2$ times higher (Fig. 3b). We also found a significant reduction of adult $S$. viridula enclosed with juvenile $S$. zebrina at the historic range overlap (SVa+SZj, Fig. 3b, Table 2). In that site, there was high mortality of juvenile S. zebrina individuals in 
the high-density treatment (i.e. independent of $S$. viridula; 4SZj; see Fig. S4 in Supporting Information). No mortality of juvenile $S$. viridula enclosed with adult or juvenile $S$. zebrina (or vice versa) was observed (Fig. S4).

Intraspecific effects (IS $\mathrm{ik}_{\mathrm{ik}}$ ) of juvenile on juvenile and adult on juvenile $S$. zebrina growth rate at the historic range overlap (i.e. white symbols in Fig. 4a: SZj-SZj, and SZa-SZj, respectively) were not significant (95\% CI cross zero; Fig. 4a). Similarly, no significant interspecific effect of $S$. viridula on $S$. zebrina (i.e. SVj-SZj, SVa-SZj) was observed (black symbols in Fig. 4a). At the leading edge of $S$. viridula at Las Cruces $\left(33^{\circ} \mathrm{S}\right)$, no significant intraspecific effect of juvenile or adult S. viridula was detected (white symbols in Fig. 4b). Instead, we found that adult $S$. zebrina had negative and significant (95\% CI do not cross zero) per capita effects on the growth rate of juvenile S. viridula (SZa-SVj, Fig. 4b).

\subsubsection{Scurria microspatial distribution in experimental cages}

Nearest neighbor distances of enclosed $S$. zebrina juvenile individuals at the historic range overlap showed a peak between zero and $40 \mathrm{~mm}$, suggesting a more aggregated pattern (see purple band in Fig. S5a, in Supporting Information) than for juvenile to adult S. zebrina conspecifics which appeared more segregated, peaking at about $200 \mathrm{~mm}$ (turquoise band in Fig. S5a). Distances of juvenile $S$. zebrina to both adult and juvenile $S$. viridula were on average between 50-80 mm (see orange and green bands, respectively, in Fig. S5a, respectively). At the leading edge of $S$. viridula, juvenile $S$. viridula individuals showed both aggregated $(0-50 \mathrm{~mm})$ and segregated $(\sim 250 \mathrm{~mm})$ intraspecific patterns through the study, (see purple band in Fig. S5b). Juvenile individuals of $S$. viridula tended to be at 
412 distances of 50-100 $\mathrm{mm}$ from both adult and juvenile $S$. zebrina individuals (see orange and 413 green bands in Fig. S5b, respectively).

\subsection{Habitat suitability at the leading edge}

416 About $54 \%$ of the coastline at the leading edge of $S$. viridula is made up of wave-exposed 417 rocky platforms, a suitable habitat for settlement, that are similar to those occupied by the

418 species in the northern part of the range. About $30 \%$ of the coastline is made up of sandy

419 beaches that are unsuitable habitat for settlement (see Fig. S6), and 9\% correspond to hard

420 artificial structures (e.g. granite breakwaters, concrete seawalls, pontoons) which are

421 interspersed among sandy and rocky habitats (see Fig. S6).

422

\section{$423 \quad 4 \mid$ DISCUSSION}

424 Our study is among the first to examine the ecological dynamics at the range overlap of 425 equivalent established and range-expanding species and that test experimentally the role of

426 biotic interactions on species range shift, linking interaction strength and spatial surveys.

427 Our field surveys, encompassing a large fraction of the geographic distribution of the two

428 Scurria species from northern to central Chile, showed that S. viridula populations have 429 recently expanded poleward to $33.33^{\circ} \mathrm{S}$, about $210 \mathrm{~km}$ south of the previously reported 430 distribution. Both juvenile and adult $S$. viridula individuals were present at this new leading

431 edge, suggesting successful colonization although at much reduced population density.

432 Field experiments showed that adult $S$. zebrina significantly reduced growth of juvenile $S$. 
viridula at its leading edge, but that $S$. viridula had no effect on $S$. zebrina at its northern

434 range limit corresponding to the historic range overlap of both species. Small scale

435 interspecific spatial segregation of individuals, which likely resulted from interference

436 competition, may reduce to some extent the deleterious effects of competition and help

437 explain the occurrence of adult S. viridula at the leading edge. Thus while there are

438 important missing pieces of information that are necessary for a full understanding of the

439 processes leading to the poleward range expansion of $S$. viridula and stasis in S. zebrina,

440 which are discussed below, our results demonstrate differential effects of interspecific

441 competition on the distribution of the two limpet species, with a potentially significant role

442 in reducing range expansion of $S$. viridula. Finally, they show that competition can be

443 asymmetric between two equivalent grazers at their range limits, with the range-expanding

444 species counterintuitively not provoking a contraction of the resident grazer species.

\section{$446 \quad 4.1$ Geographic distribution and Scurria occurrence}

447 A decline in abundance towards a species' range boundary is often interpreted as evidence

448 of a reduction in individual success (i.e. growth rate, survival probability), and is usually

449 assumed to reflect a decline in suitable environmental conditions (e.g. Brown et al., 1996;

450 Case \& Taper, 2000). In our study, however, comparatively high growth rates and the

451 occurrence of both juvenile and adult $S$. viridula at its leading edge suggests that

452 environmental conditions are not limiting the performance of this species toward its range

453 edge. S. viridula juvenile individuals had a positive mean growth rate $(0.0172 \pm 0.0026 \mathrm{~g} \times$

$\left.454 \mathrm{day}^{-1}\right)$ at natural densities in the enclosure experiment at the leading edge $\left(2 \mathrm{ind} . / 900 \mathrm{~cm}^{2}\right)$,

455 which was similar to the growth rate observed at Punta Talca, further north $(0.0174 \pm$ 
457 at the leading edge had a marginal but non-significant effect on the growth rate of $S$.

458 viridula individuals $\left(0.0157 \pm 0.0011 \mathrm{~g} \times\right.$ day $\left.^{-1}\right)$. These results suggest that even under the 459 potentially stressful conditions experienced by individuals at a leading edge of distribution 460 (e.g. Fenberg \& Rivadeneira, 2011), S. viridula can sustain similar individual growth rates 461 to those observed at sites towards the center of the range. This raises the question of why 462 the expanding species is being negatively affected by interspecific competition, even when 463 individuals do not seem to be compromised physiologically by environmental constraints.

\subsection{Competition and species range overlap}

466

467

468

469

470

471

472

473

474

Experimental and manipulative tests of the role of competition in setting species range edges remain scarce, largely due to the logistic difficulties associated with scaling up local processes to large scales (see for example Cunningham et al., 2009; Davis, Jenkinson, Lawton, Schorrocks, \& Wood, 2001; Godsoe et al., 2015; Hu \& Jiang, 2018). Our study is therefore a timely experimental demonstration of the importance of considering local interspecific interactions when interpreting range shifts of species. Grazing limpets compete for space and food on many rocky shores (e.g. Branch, 1976; Creese \& Underwood, 1982; Boaventura et al., 2002; Firth \& Crowe, 2010; Aguilera \& Navarrete, 2012). However, food supply (e.g. microalgae and ephemeral algae) is expected to be relatively high across the range considered in our study due to high nutrient availability (Wieters, 2005). In our field experimental plots the main algal items consumed by the Scurria species were present even at the end of the experiments (see Table S3 in Supporting Information). Exploitation competition for food may therefore be less important 
479 than other kinds of competition, such as interference, among Scurria limpets. The existence 480 of competition under natural conditions is supported by the observations of small-scale 481 spatial segregation between adult Scurria species at scales of $\sim 150 \mathrm{~mm}$ (Aguilera et al., 482 2013, this study). Although different processes may affect individual-to-individual 483 distances in limpets, such as substratum topographic complexity (Chapman \& Underwood, 484 1994) and micro-spatial thermal patterns (Chapperon \& Seuront, 2011), interspecific 485 individual encounter reduction by individual dispersion has been described as an effective 486 way to reduce interspecific competition (Branch, 1975). Micro-scale segregation may allow 487 a few individuals of $S$. viridula grow to adult size, and if so it may play some role in 488 facilitating local coexistence. However, the low population densities suggest that the small 489 segregation is insufficient to overcome the deleterious effects of competition on individual 490 performance and allow local populations to sustain positive population growth when rare, a 491 necessary requirement to allow for stable coexistence (Chesson, 2000; Shinen \& Navarrete, 492 2014; Siepielski \& Mcpeek, 2010).

493 Our experimental manipulations support the hypothesis of asymmetric interspecific 494 competition: we found lower growth rates of juvenile $S$. viridula at its leading edge when 495 enclosed with adult $S$. zebrina. While this competitive effect could lead to the eventual 496 local extinction of the expanding S. viridula by the local S. zebrina, competitive exclusion 497 is not necessary for competition to play a major role in stopping the advancement of an 498 invader or range-expanding species. For example, interspecific competition could reduce 499 larval output below the level that guarantees a minimum level of self-replenishment (Aiken 500 \& Navarrete, 2014; Lett, Nguyen-Huu, Cuif, Saenz-Agudelo, \& Kaplan, 2015) of the 501 invading species. This can make leading populations the sink of larvae produced from 
upstream populations, which might halt the advancing front some distance downstream

503 from the last self-maintained population. Interestingly, population size plays an important

504 role in the leading range edge of species with longer pelagic larval development (Pringle,

505 Byers, He, Pappalardo, \& Wares, 2017), highlighting the indirect role that competition can

506 play in species with large dispersal potential. Since other species with pelagic larvae are

507 expanding their distributions at comparable rates to those of S. viridula in the eastern

508 Pacific (e.g. the limpet Lottia orbignyi; $13.8 \mathrm{~km}^{*} \mathrm{year}^{-1}$, the whelk Thais haemastoma;

$50915.9 \mathrm{~km}^{*}$ year $\left.^{-1}\right)($ Rivadeneira \& Fernández, 2005; Sorte, Williams, \& Carlton, 2010), it

510 would be interesting to evaluate the role of biotic resistance by means of competition of the

511 native assemblage in influencing species' range shift. Our main results suggest competitive

512 interactions could have an important role influencing the geographic distribution of

513 equivalent species in combination with physical and biotic processes operating on larval

514 dispersal and settlement.

\subsection{Habitat suitability and Scurria range limits}

517 The combination of scarcity of suitable habitat and dispersal limitation is one of the main

518 mechanisms determining species' range borders (Brown et al., 1996; Case et al., 2005; Holt

$519 \&$ Keitt, 2005). In the absence of dispersal information, our examination of the role of

520 habitat suitability in limiting $S$. viridula expansion by exploring the availability of suitable

521 (rocky shore) versus unsuitable (sandy beach) habitat across the leading edge seems useful

522 in this context (e.g. Fenberg \& Rivadeneira, 2011; see Fig. S6 in Supporting Information).

523 We found that the coastline present at the leading edge of $S$. viridula is predominantly

524 (>51\%) made up of wave-exposed rocky platforms that are similar to those occupied by the 
525 species in the northern part of the range. However, 30\% is made up of sandy beaches

526 (unsuitable habitat; see Fig. S6). Extensive sandy beaches present in this area ( 8-12 km

527 long) could represent a barrier for the dispersal of species with short pelagic larval duration

528 (PLD) (Lester, Ruttenberg, Gaines, \& Kinlan, 2007), although most numerical models of

529 realistic coastal oceans suggest that even species with PLD of 5-10 days can disperse from

530 tens to hundreds of kilometers (Aiken \& Navarrete, 2014; Lett et al. 2015). Therefore, it is

531 unlikely that the observed sandy beaches within the region represent an important dispersal

532 barrier. We found that about $\sim 9 \%$ of the coastline is made up of hard artificial structures,

533 which are interspersed among sandy and rocky habitats (see Fig. S6). Previous studies have

534 shown that artificial infrastructures like breakwaters can reduce distances between

535 populations and serve as "stepping-stones" for the dispersal of rocky intertidal species with

536 limited dispersal capacity (Dong, Huang, Wang, Li, \& Wang, 2016; Firth et al., 2016).

537 Scurria viridula commonly uses artificial breakwaters and seawalls as habitat, especially in

538 highly urbanized coasts such as in central Chile (MA Aguilera unpublished), further

539 assisting effective dispersal across sandy beaches.

5415 | Concluding remarks

542 Our results suggest that an ecological interaction such as asymmetric competition could

543 contribute to maintain stability in the location of a species range overlap (i.e. populations

544 are prevented from advancing for a period of time; Phillips, 2012). Our results show that

545 juveniles of an advancing species can be sensitive to interference by the native or

546 established species potentially leading to the inhibition of expansion. Our observations also

547 suggest that fine-scale spatial segregation between grazer species could facilitate further 
548 poleward expansion. If the range-expanding grazer is successful at settling in artificial

549 substrata, it may suggest a trade-off in competitive versus colonization abilities between the

550 species (Tilman, 1994). Therefore asymmetrical competition, finer-scale niche segregation

551 and opportunistic exploitation of novel habitats may be critical to understand the

552 mechanisms contributing to maintain the stability of species ranges.

553

554 Acknowledgements

555 This research was funded by FONDECYT \#11121360 and \#1160223, and PAI-CONICYT

$556 \# 79150002$ to M.A.A. B.R.B. acknowledges support from MINECON ICM Nucleus

557 MUSELS and FONDECYT grant \# 1181300. Additional support for field trips was

558 provided by FONDECYT \#1160289 to S.A.N. N.V. was supported by FONDECYT grants

$559 \quad \# 1141037$ and \#1161699 and FONDAP grant \#15150003. Alexandra Gangas supported the

560 sampling of limpets in the southern range financed by FONDECYT \#11121360. We thank

561 Tomás Flores, Mauricio Oróstica, Ariel Rojas and Tatiana Manzur for field assistance. We

562 thanks to three anonymous reviewers and the Associate Editor, who made very helpful

563 comments and suggestions to improve the final version of the manuscript.

564

565 Author contributions: M.A. conceived the idea; M.A., N.V. conduct the surveys; M.A.,

566 S.A.N. design the field experiments; M.A. conduct the field experiments and analyzed the

567 data; M.A., N.V., B.B., S.A.N. and S.J. wrote the paper.

568

569

Data Accessibility.

570 Data associated with this manuscript will be available in the Dryad Digital Repository.

571 Supporting Information.

572 Fig. S1. Scatterplot of the density of Scurria species recorded along the coast of Chile.

573 Fig. S2. Shell size of Scurria species measured at different latitudes. 
574 Fig. S3. Heterospecific individual nearest neighbor distances measured for both Scurria 575 species at HRO and LE.

576 Fig. S4. Total number of dead individuals found in enclosures in field experiments.

577 Fig. S5. Density plot of the intra and heterospecific nearest neighbor distances estimated 578 inside experimental enclosures.

579 Fig. S6. Proportion of suitable and unsuitable habitat from $32^{\circ} \mathrm{S}$ to $33^{\circ} \mathrm{S}$ for S. viridula 580 expansion.

581 Table S1. Summary of localities sampled during the study and details of field surveys.

582 Table S2. Pearson's spatial correlation between Scurria species.

583 Table S3. Average percent cover (\%) of algal groups present inside experimental 584 enclosures at the end of field experiments.

585 Appendix S1. Nearest neighbor distance distribution analyses.

586 Appendix S2. Field experimental procedures, design and set up.

587 Appendix S3. Details of interaction strength estimations for field experiments. 


\section{REFERENCES}

594

595

596

597

598

599

600

601

602

603

604

605

606

607

608

609

610

611

612

613

614

615

616

617

618

619

620

621

622

623

624

625

Aguilera, M. A., \& Navarrete, S. A. (2012). Interspecific competition for shelters in territorial and gregarious intertidal grazers: consequences for individual behaviour. PLoS ONE, 7(9), e46205. doi:10.1371/journal.pone.0046205

Aguilera, M. A., Valdivia, N., \& Broitman, B. R. (2013). Spatial niche differentiation and coexistence at the edge: co-occurrence distribution patterns in Scurria limpets. Marine Ecology Progress Series, 483, 185-198. doi:10.3354/meps 10293

Aguirre, C., Pizarro, Ó., Strub, P. T., Garreaud, R., \& Barth, J. A. (2012). Seasonal dynamics of the near-surface alongshore flow off central Chile. Journal of Geophysical Research: Oceans, 117(November 2011), 1-17. doi:10.1029/2011JC007379

Aiken, C. M., \& Navarrete, S. A. (2014). Coexistence of competitors in marine metacommunities: Environmental variability, edge effects, and the dispersal niche. Ecology, 95(8), 2289-2302. doi:10.1890/13-0472.1

Araújo, M. B., \& Luoto, M. (2007). The importance of biotic interactions for modelling species distributions under climate change. Global Ecology and Biogeography, 16, 743-753. doi:10.1111/j.1466-8238.2007.00359.x

Araújo, M. B., \& Rozenfeld, A. (2013). The geographic scaling of biotic interactions. Ecography, 37, 406-415. doi:10.1111/j.1600-0587.2013.00643.x

Boaventura, D., Cancela Da Fonseca, L., \& Hawkins, S. J. (2002). Analysis of competitive interactions between the limpets Patella depressa Pennant and Patella vulgata L. on the northern coast of Portugal. Journal of Experimental Marine Biology and Ecology, 271, 171-188. doi:10.1016/S0022-0981(02)00044-8

Boaventura, D., Cancela, L., Fonseca, D., \& Hawkins, S. J. (2003). Size Matters : competition within populations of the limpet Patella depressa. Journal of Animal Ecology, 72(3), 435-446.

Bolker, B., \& Pacala, S. W. (1997). Using moment equations to understand stochastically driven spatial pattern formation in ecological systems. Theoretical Population Biology, 52, 179-197. doi:10.1006/tpbi.1997.1331

Branch, G. (1975). Mechanisms reducing intraspecific competition in Patella spp .: migration, differentiation and territorial behaviour. Journal of Animal Ecology, 44(2), $575-600$. 
626

627

628

629

630

631

632

633

634

635

636

637

638

639

640

641

642

643

644

645

646

647

648

649

650

651

652

653

654

655

656

657

658

659

660

Branch, G. (1976). Interspecific competition experienced by South African Patella species Journal. Journal of Animal Ecology, 45, 507-529.

Broitman, B. R., Aguilera, M. A., Lagos, N. A., \& Lardies, M. A. (2018). Phenotypic plasticity at the edge: contrasting population level responses at the overlap of the leading and rear edges of the geographical distribution of two Scurria limpets. Journal of Biogeography, in press.

Broitman, B. R., Véliz, F., Manzur, T., Wieters, E. A., Finke, R., Fornes, P., ... Navarrete, S. A. (2011). Geographic variation in diversity of wave exposed rocky intertidal communities along central Chile. Revista Chilena de Historia Natural, 143, 143-154.

Brown, J. H. (1984). On the relationship between abundance and distribution of species. The American Naturalist, 124, 255-279.

Brown, J. H., Stevens, G. C., \& Kaufman, D. M. (1996). The geographic range: size, shape, and internal structure. Annual Review of Ecology and Systematics, 27, 597-623. doi:10.1146/annurev.ecolsys.27.1.597

Camus, P., Daroch, K., \& Opazo, L. (2008). Potential for omnivory and apparent intraguild predation in rocky intertidal herbivore assemblages from northern Chile. Marine Ecology Progress Series, 361, 35-45. doi:10.3354/meps07421

Case, T. J., Holt, R. D., Mcpeek, M. A., \& Keitt, T. H. (2005). The community context of species ' borders : ecological and evolutionary perspectives. Oikos, 108, 28-46.

Case, T. J., \& Taper, M. (2000). Interspecific competition, environmental gradients, gene flow, and the coevolution of species' borders. The American Naturalist, 155, 583-605.

Chapman, M. G., \& Underwood, A. J. (1994). Dispersal of the intertidal snail, Nodilittorina pyramidalis, in response to the topographic complexity of the substratum. Journal of Experimental Marine Biology and Ecology, 179(94), 145-169. doi:10.1016/00220981(94)90111-2

Chapperon, C., \& Seuront, L. (2011). Space-time variability in environmental thermal properties and snail thermoregulatory behaviour. Functional Ecology, 25(5), 10401050. doi:10.1111/j.1365-2435.2011.01859.x

Chesson, P. (2000). Mechanisms of maintenance of species diversity. Annual Review of Ecology and Systematics, 31, 343-358. Retrieved from http://www.jstor.org/stable/10.2307/221736

Cunningham, H. R., Rissler, L. J., \& Apodaca, J. J. (2009). Competition at the range boundary in the slimy salamander : using reciprocal transplants for studies on the role of biotic interactions in spatial distributions. Journal of Animal Ecology, 52-62. doi:10.1111/j.1365-2656.2007.0 
661

662

663

664

665

666

667

668

669

670

671

672

673

674

675

676

677

678

679

680

681

682

683

684

685

686

687

688

689

690

691

692

693

694

695

Davis, A. J., Jenkinson, L. S., Lawton, J. H., Schorrocks, B., \& Wood, S. N. (2001). Making mistakes when predicting shifts in species range in response to global warming. Nature, 409, 363-366. doi:10.1038/35055575

Dixon, P. (2009). Testing spatial segregation using a nearest-neighbor contingency table. Ecology, 75(7), 1940-1948.

Dong, Y. W., Huang, X. W., Wang, W., Li, Y., \& Wang, J. (2016). The marine "great wall” of China: Local- and broad-scale ecological impacts of coastal infrastructure on intertidal macrobenthic communities. Diversity and Distributions, 22, 731-744. doi:10.1111/ddi.12443

Dutilleul, P. (1993). Spatial heterogeneity and the design of ecological field experiments. Ecology, 74(6), 1646-1658.

Espoz, C., Lindberg, D. R., Castilla, J. C., \& Simison, W. B. (2004). Los patelogastrópodos intermareales de Chile y Perú. Revista Chilena de Historia Natural, 77(1), 257-283.

Fenberg, P. B., \& Rivadeneira, M. M. (2011). Range limits and geographic patterns of abundance of the rocky intertidal owl limpet, Lottia gigantea. Journal of Biogeography, 38, 2286-2298. doi:10.1111/j.1365-2699.2011.02572.x

Firth, L. B., Crowe, T. P., Moore, P., Thompson, R. C., \& Hawkins, S. J. (2009). Predicting impacts of climate-induced range expansion: An experimental framework and a test involving key grazers on temperate rocky shores. Global Change Biology, 15, 14131422. doi:10.1111/j.1365-2486.2009.01863.x

Firth, L. B., Knights, A. M., Bridger, D., Evans, A. J., Mieszkowska, N., Moore, P. J., ... Hawkins, S. J. (2016). Ocean Sprawl: Challenges and Opportunities for Biodiversity Management in a Changing World. Oceanography and Marine Biology Annual Review, 54, 193-269.

Fortin, M.-J., \& Dale, M. R. T. (2005). Spatial Analysis: a guide to ecologists (Fourth, p. 360). Cambridge: Cambridge University Press.

Gilman, S. E. (2006). The northern geographic range limit of the intertidal limpet Collisella scabra: A test of performance, recruitment, and temperature hypotheses. Ecography, 29(June), 709-720. doi:10.1111/j.0906-7590.2006.04572.x

Godsoe, W., \& Harmon, L. J. (2012). How do species interactions affect species distribution models? Ecography, 35(9), 811-820. doi:10.1111/j.16000587.2011.07103.x

Godsoe, W., Jankowski, J., Holt, R. D., \& Gravel, D. (2017). Integrating biogeography with contemporary niche theory. Trends in Ecology and Evolution, 32(7), 488-499. doi:10.1016/j.tree.2017.03.008 
696

697

698

699

700

701

702

703

704

705

706

707

708

709

710

711

712

713

714

715

716

717

718

719

720

721

722

723

724

725

726

727

728

Godsoe, W., Murray, R., \& Plank, M. J. (2015). The effect of competition on species' distributions depends on coexistence, rather than scale alone. Ecography, 38(December 2014), 1071-1079. doi:10.1111/ecog.01134

Holt, R. D., \& Keitt, T. H. (2005). Species' borders: a unifying theme in ecology. Ecography, 1, 3-6.

Hu, J., \& Jiang, J. (2018). Inferring ecological explanations for biogeographic boundaries of parapatric Asian mountain frogs. BMC Ecology, 18, 1-11. doi:10.1186/s12898-0180160-5

Lasiak, T. A., \& White, D. R. (1993). Microalgal food resources and competitive interactions among the intertidal limpets Cellana capensis (Gmelin, 1791) and Siphonaria concinna Sowerby, 1824. South African Journal of Marine Science, 13, 97-108. doi:10.2989/025776193784287419

Lester, S., Ruttenberg, B. I., Gaines, S. D., \& Kinlan, B. P. (2007). The relationship between dispersal ability and geographic range size. Ecology, 10, 745-758. doi:10.1111/j.1461-0248.2007.01070.x

Lett, C., Nguyen-Huu, T., Cuif, M., Saenz-Agudelo, P., \& Kaplan, D. M. (2015). Linking local retention, self-recruitment, and persistence in marine metapopulations. Ecology, 96(8), 2236-2244. doi:10.1890/14-1305.1

Marshall, P. A., \& Keough, M. J. (1994). Asymmetry in intraspecific competition in the limpet Cellana tramoserica (sowerby). Journal of Experimental Marine Biology and Ecology, 177, 121-138. doi:10.1016/0022-0981(94)90147-3

Navarrete, S. A., Wieters, E. A., Broitman, B. R., \& Castilla, J. C. (2005). Scales of benthic-pelagic coupling and the intensity of species interactions: from recruitment limitation to top-down control. Proceedings of the National Academy of Sciences of the United States of America, 102, 18046-18051. doi:10.1073/pnas.0509119102

Phillips, B. L. (2012). Range shift promotes the formation of stable range edges. Journal of Biogeography, 39(January 2012), 153-161. doi:10.1111/j.1365-2699.2011.02597.x

Pigot, A. L., \& Tobias, J. A. (2013). Species interactions constrain geographic range expansion over evolutionary time. Ecology Letters, 16, 330-338. doi:10.1111/ele.12043

Pringle, J., Byers, J. E., He, R., Pappalardo, P., \& Wares, J. (2017). Ocean currents and competitive strength interact to cluster benthic species range boundaries in the coastal ocean. Marine Ecology-Progress Series, 567, 29-40. 
Rivadeneira, M. M., \& Fernández, M. (2005). Shifts in southern endpoints of distribution in rocky intertidal species along the south-eastern Pacific coast. Journal of Biogeography, 32, 203-209. doi:10.1111/j.1365-2699.2004.01133.x

Rivadeneira, M. M., Hernáez, P., Antonio Baeza, J., Boltaña, S., Cifuentes, M., Correa, C., ... Thiel, M. (2010). Testing the abundant-centre hypothesis using intertidal porcelain crabs along the Chilean coast: Linking abundance and life-history variation. Journal of Biogeography, 37, 486-498. doi:10.1111/j.1365-2699.2009.02224.x

Sagarin, R., \& Gaines, S. (2002). The "abundant centre"distribution: to what extent is it a biogeographical rule? Ecology Letters, 5, 137-147. Retrieved from http://onlinelibrary.wiley.com/doi/10.1046/j.1461-0248.2002.00297.x/full

Shinen, J. L., \& Navarrete, S. A. (2014). Lottery Coexistence on rocky shores: weak niche differentiation or equal competitors engaged in neutral dynamics? The American Naturalist, 183(3), 342-362. doi:10.1086/674898

Siepielski, A., \& Mcpeek, M. A. (2010). On the evidence for species coexistence: a critique of the coexistence program. Ecology, 91(11), 3153-3164.

Soberón, J. M. (2010). Niche and area of distribution modeling: A population ecology perspective. Ecography, 33(November), 159-167. doi:10.1111/j.16000587.2009.06074.x

Sorte, C. J. B., Williams, S. L., \& Carlton, J. T. (2010). Marine range shifts and species introductions: Comparative spread rates and community impacts. Global Ecology and Biogeography, 19, 303-316. doi:10.1111/j.1466-8238.2009.00519.x

Tilman, D. (1994). Competition and biodiversity in spatially structured habitats. Ecology, 75, 2-16.

Vermeij, G. J. (2005). From Europe to America: pliocene to recent trans-Atlantic expansion of cold-water North Atlantic molluscs. Proceedings of the Royal Society B: Biological Sciences, 272(September), 2545-2550. doi:10.1098/rspb.2005.3177

Wieters, E. A. (2005). Upwelling control of positive interactions over mesoscales: a new link between bottom-up and top-down processes on rocky shores. Marine Ecology Progress Series, 301, 43-54. 
764 Figure 1. Schematic model system and map of the geographic overlap of Scurria species

765 and experimental set-up. Previous Scurria occurrences generated an historic range overlap, 766 (HRO) at $30^{\circ} \mathrm{S}$ to $32^{\circ} \mathrm{S}$ (also indicated as green arrows in the map). Recent (2013) evidence 767 suggests Scurria viridula expanded its polar range edge (dotted red line) conforming a new 768 leading edge (LE) (around 3330'S). Red and blue lines show the model (scheme) and real 769 (map) range distribution of S. viridula and S. zebrina, respectively, along the coast of Chile. 770 Green arrows in the map show also the locations were field experiments were performed.

771 Field experiments (see boxes for intra- and interspecific effects) were conducted at both 772 HRO and LE, which test the role of competition in contributing to reduce range expansion 773 and promote range contraction. It was expected that at their historic range overlap $S$. 774 viridula would reduce the growth rate of $S$. zebrina promoting its contraction (red arrow), 775 while at the leading edge, it was expected $S$. zebrina might contribute to reduction of $S$. 776 viridula expansion (blue arrow). Given both Scurria species populations present at their 777 range edge are composed of juvenile individuals, and have lower densities, field 778 experiments considered competitive effects of different size classes; adult (S. zebrina; SZa, 779 S. viridula; $\mathrm{SVa})$ and juvenile $(\mathrm{SZj}, \mathrm{SVj})$ individuals, and natural $(\times 2$ individuals; intra-and 780 interspecific) and increased ( $\times 4$ individuals; intraspecific) densities for both Scurria 781 species. 
Figure 2. Latitudinal occurrence (i.e. the proportion of quadrats were a species was found)

785 of Scurria viridula and S. zebrina observed from $18^{\circ} \mathrm{S}$ to $41^{\circ} \mathrm{S}$ along the coast of Chile.

786 The red box show the geographic range where the species co-occur in north-central Chile,

787 their historic range overlap (HRO), while the dotted-blue box depicts the leading edge of $S$.

788 viridula (LE). A map of Chile is shown below, indicating (with blue arrows) the northern

$789\left(18^{\circ} \mathrm{S}\right)$ and southern $\left(41^{\circ} \mathrm{S}\right)$ sites considered in the geographic surveys and the Scurria

790 species range overlap (dotted red lines).

791

792 Figure 3. Average ( \pm SE) change in wet weight of Scurria zebrina (a) and S. viridula (b)

793 recorded in experimental arenas at the historic range overlap and the leading edge of $S$.

794 viridula. SZ: S. zebrina, SV: S. viridula. Subscripts “j” and "a” denote "juvenile” and

795 "adult" individuals for each species. Means with the same letters were not statistically

796 significant by Tukey's multiple comparison test $(\alpha=0.05)$.

798 Figure 4. Per capita intraspecific effects (white symbols), and 'pure' interspecific effects

799 (black symbols) on growth rate (wet weight), estimated for juvenile on juvenile, juvenile on

800 adult and adult on juvenile individuals of the corresponding focal species considered in

801 field experiments conducted at the historic range overlap (a) and at the leading edge of $S$.

802 viridula (b). Bars correspond to confidence intervals (95\%) estimated by a bootstrapping

803 procedure. Subscripts "j" and "a" denote "juvenile" and "adult" individuals, respectively. 

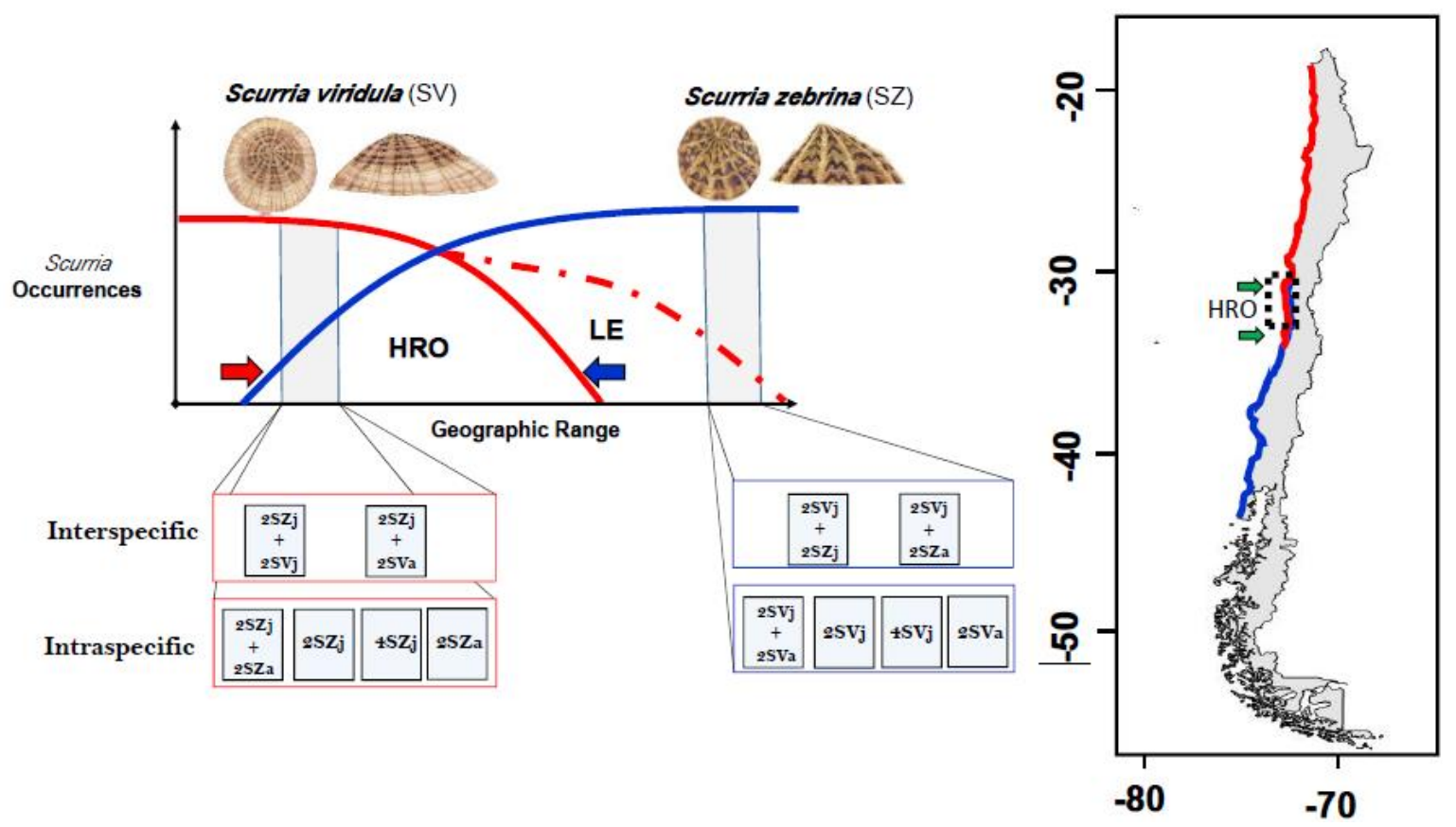

806

807

Figure 1

808 


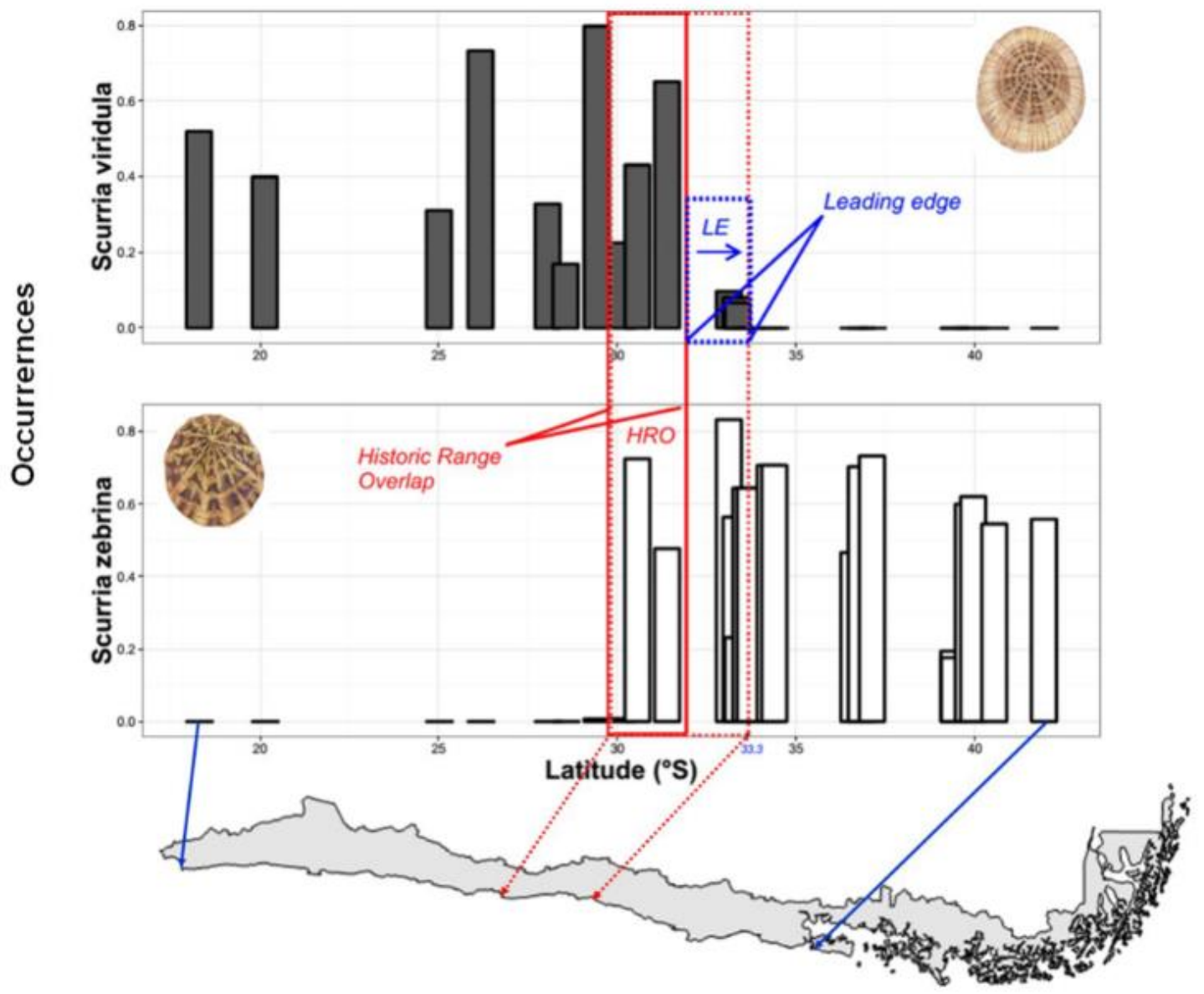

809

$810 \quad$ Figure 2

811 
a)

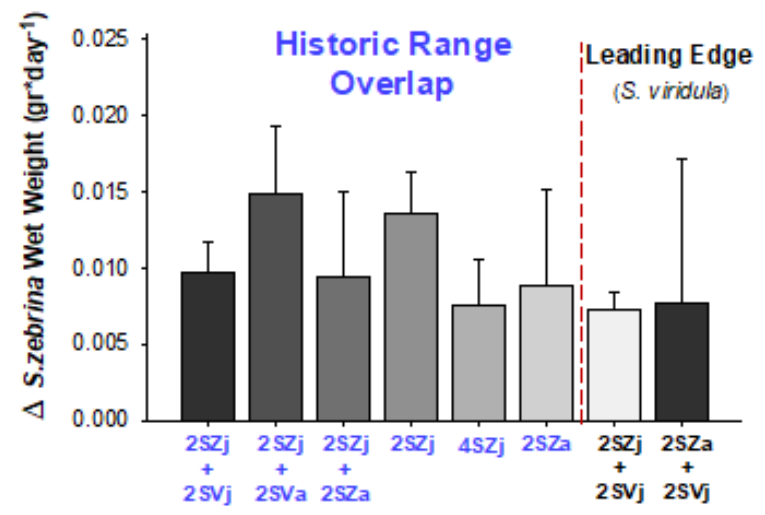

b)

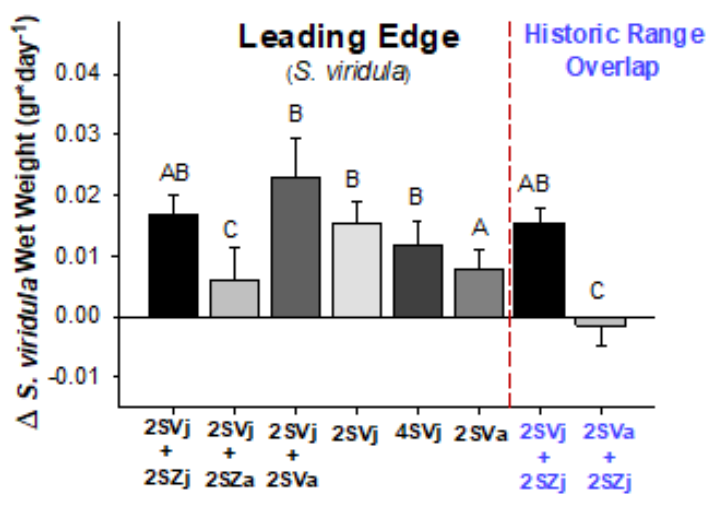

812

813

Figure 3

814

815 
Supporting Information. Figures, tables \& Appendices

819

820

821

822

823

824

825

826

827

828

829

830

831

832

833

834

835

836

837

838

839

840

\title{
Asymmetric competitive effects during species range expansion: an experimental assessment of interaction strength between 'equivalent' grazer species at their range overlap
}

\author{
Moisés A. Aguilera ${ }^{1}$, Nelson Valdivia ${ }^{2}$, Sergio A. Navarrete ${ }^{4}$ and Stuart Jenkins ${ }^{5}$ Bernardo \\ Broitman $^{3}$ \\ ${ }^{1}$ Departamento de Biología Marina, Facultad de Ciencias del Mar, Universidad Católica del Norte, Larrondo 1281, \\ Coquimbo, Chile \\ ${ }^{2}$ Centro de Estudios Avanzados en Zonas Áridas (CEAZA) Ossandón 877, Coquimbo, Chile. \\ ${ }^{3}$ Instituto de Ciencias Marinas y Limnológicas, Facultad de Ciencias, Universidad Austral de Chile, Campus Isla Teja \\ s/n, Valdivia, Chile \\ ${ }^{4}$ Centro FONDAP de Investigación en Dinámica de Ecosistemas Marinos de Altas Latitudes (IDEAL) \\ ${ }^{5}$ Estación Costera de Investigaciones Marinas, Las Cruces, LINCGlobal and Center for Applied Ecology and \\ Sustainability, Pontificia Universidad Católica de Chile, Casilla 114-D, Santiago, Chile. \\ ${ }^{6}$ School of Ocean Sciences, Bangor University, Menai Bridge, Anglesey LL59 5AB, UK
}

Supporting Information.

Fig. S1. Scatterplot of the density of Scurria species recorded along the coast of Chile.

Fig. S2. Shell size of Scurria species measured at different latitudes. 
841 Fig. S3. Heterospecific individual nearest neighbor distances measured for both Scurria 842 species at HRO and LE.

843 Fig. S4. Total number of dead individuals found in enclosures in field experiments.

844 Fig. S5. Density plot of the intra and heterospecific nearest neighbor distances estimated 845 inside experimental enclosures.

846 Fig. S6. Proportion of suitable and unsuitable habitat from $32^{\circ} \mathrm{S}$ to $33^{\circ} \mathrm{S}$ for S. viridula 847 expansion.

848 Table S1. Summary of localities sampled during the study and details of field surveys.

849 Table S2. Pearson's spatial correlation between Scurria species.

850 Table S3. Average percent cover (\%) of algal groups present inside experimental 851 enclosures at the end of field experiments.

852

853 Appendix S1. Nearest neighbor distance distribution analyses.

854 Appendix S2. Field experimental procedures, design and set up.

855 Appendix S3. Details of interaction strength estimations for field experiments. 
865

866

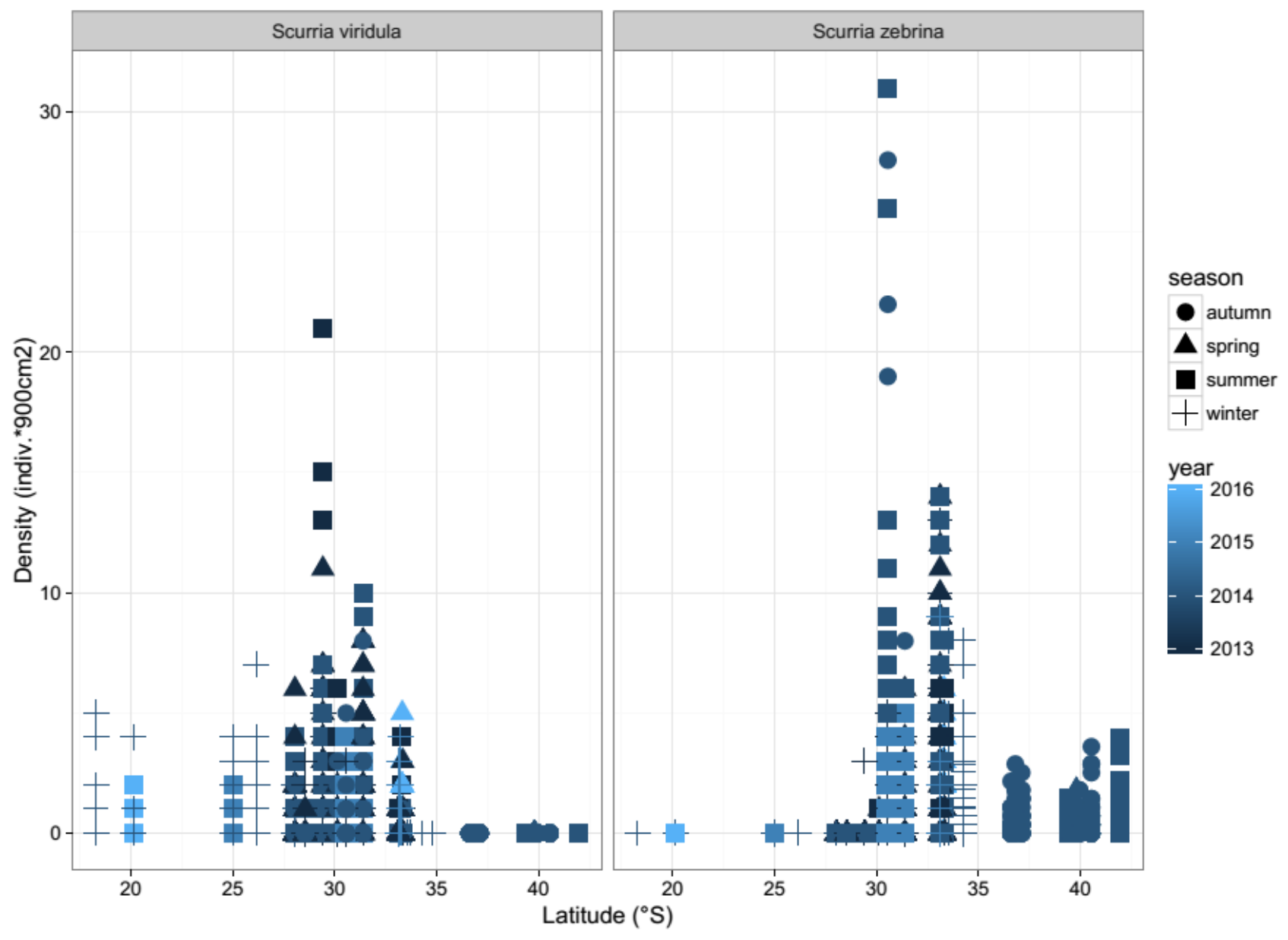

871 Fig. S1. Scatterplot of the density (indiv. per quadrat) of both S.viridula and S. zebrina, 872 recorded along the coast of Chile (from $18^{\circ} \mathrm{S}$ to $41^{\circ} \mathrm{S}$ ) at different platforms, sites, seasons 873 and years.

874

875

876

877 
a) Scurria viridula

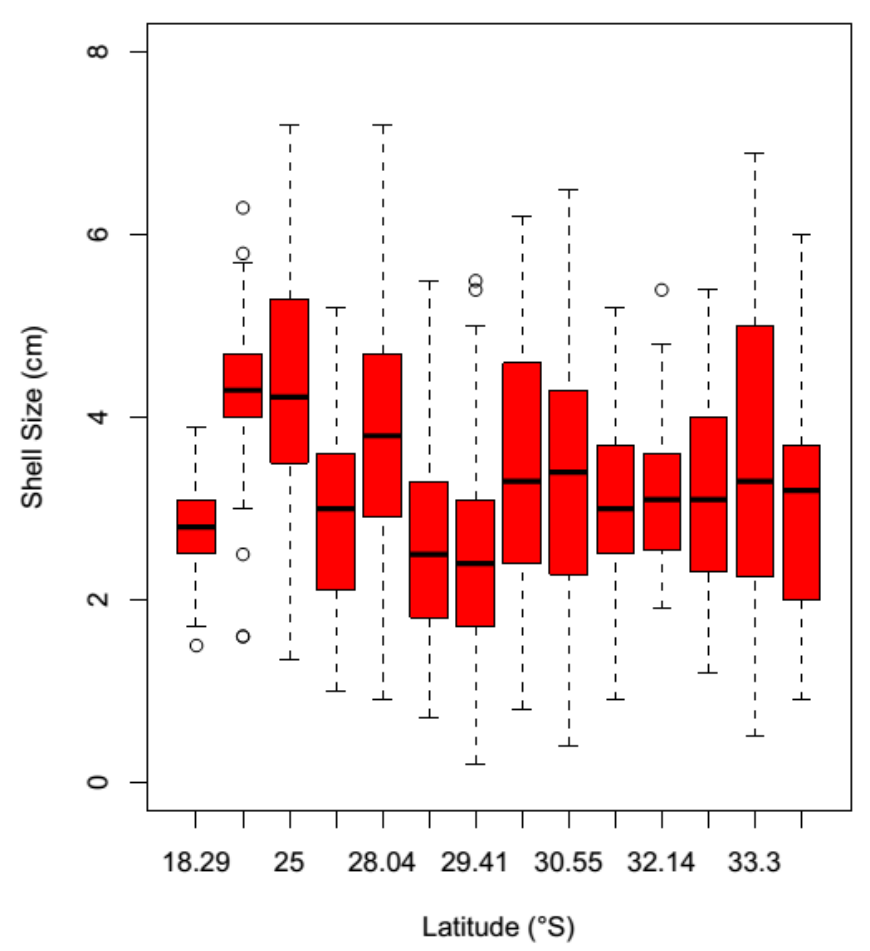

b) Scurria zebrina

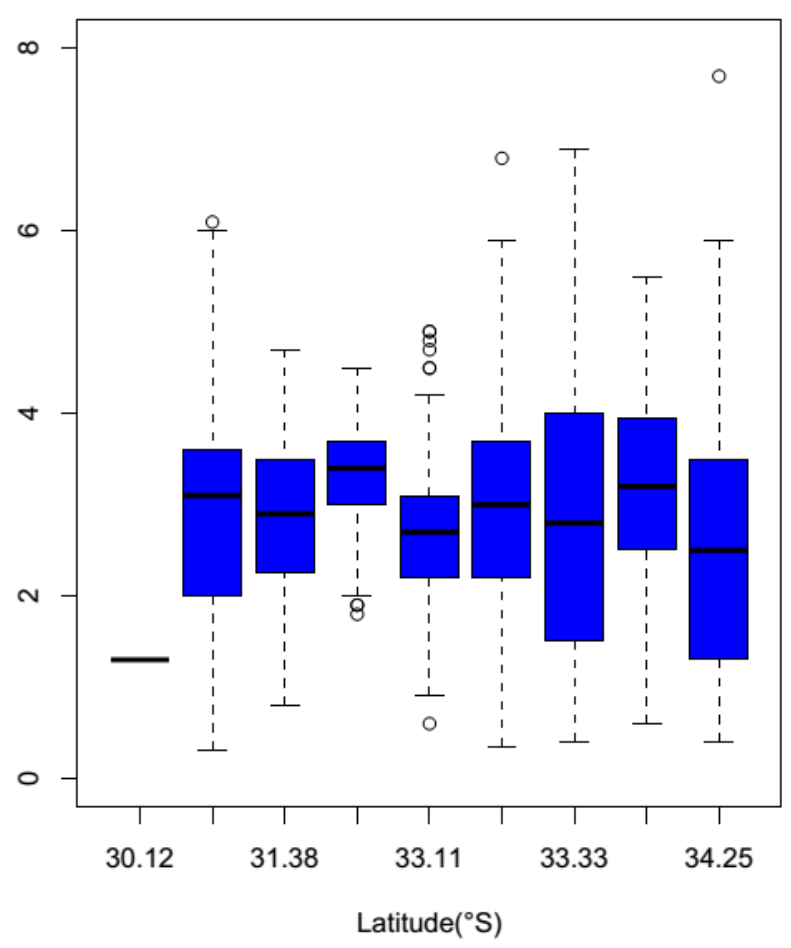

Fig. S2. Box plots of shell size of a) S. viridula (red) and b) S. zebrina (blue) across different latitudes from north to central Chile. The black line in each box is the median, the boxes define the hinge (25-75\% quartile, and the line is 1.5 times the hinge). Points outside the interval (outliers) are represented as dots 


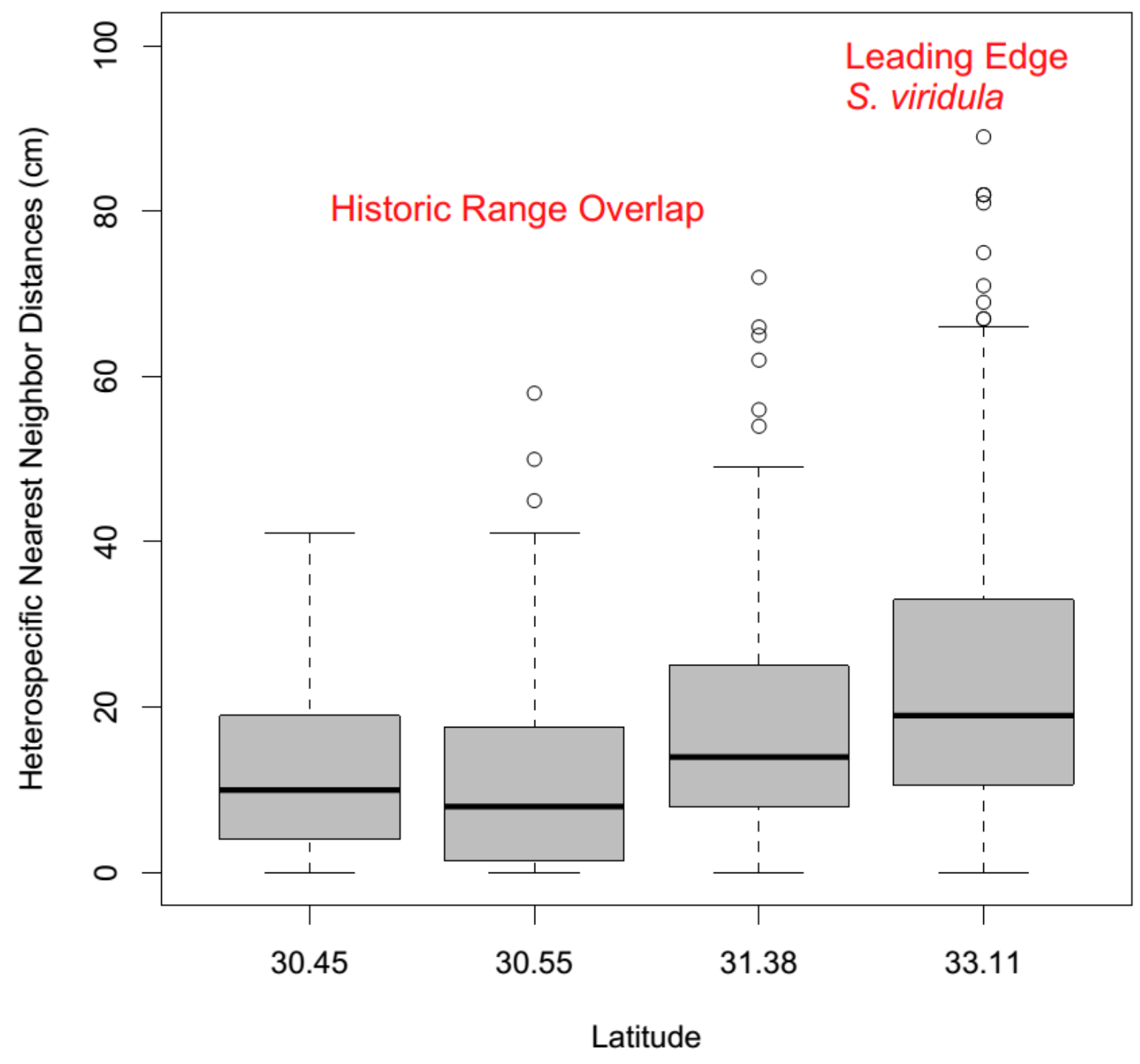

891 Fig. S3. Box plots of the heterospecific (S. viridula to S. zebrina) individual nearest 892 neighbor distances, estimated in the field across the Scurria historic range overlap and at 893 the leading edge of $S$. viridula (Quintay; 33.11 ${ }^{\circ} \mathrm{S}$ ).

894

895

896 
Historic Range Overlap (HRO)

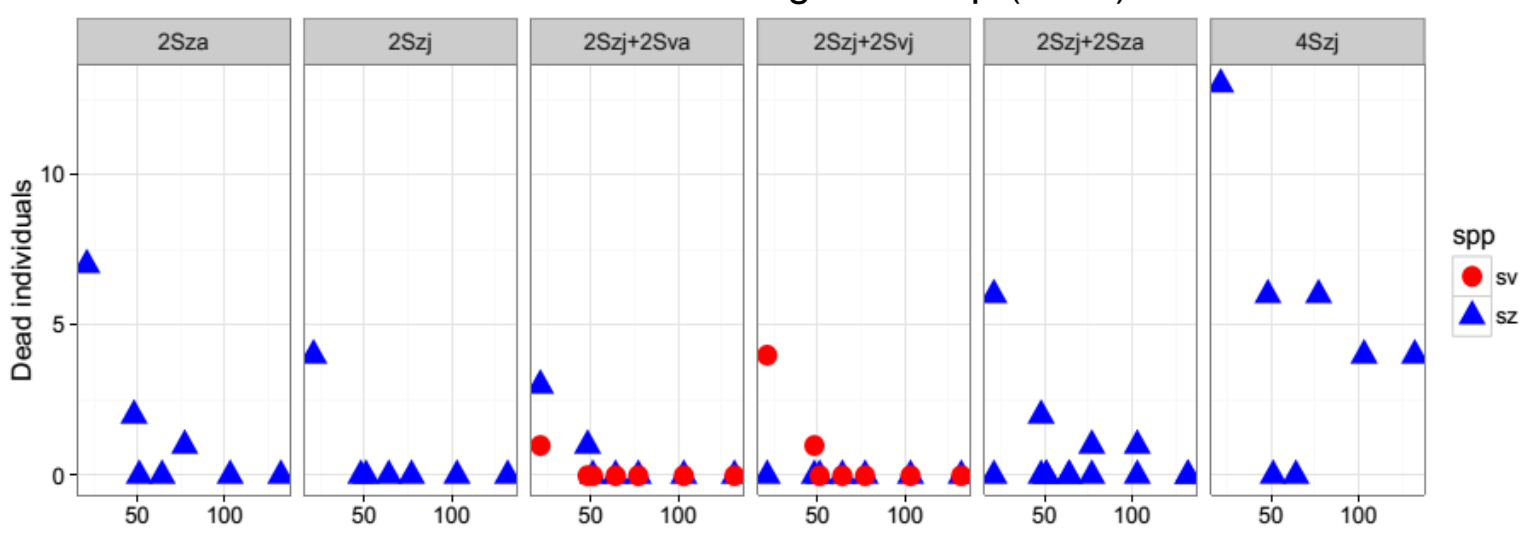

Leading edge of $S$. viridula (LED)
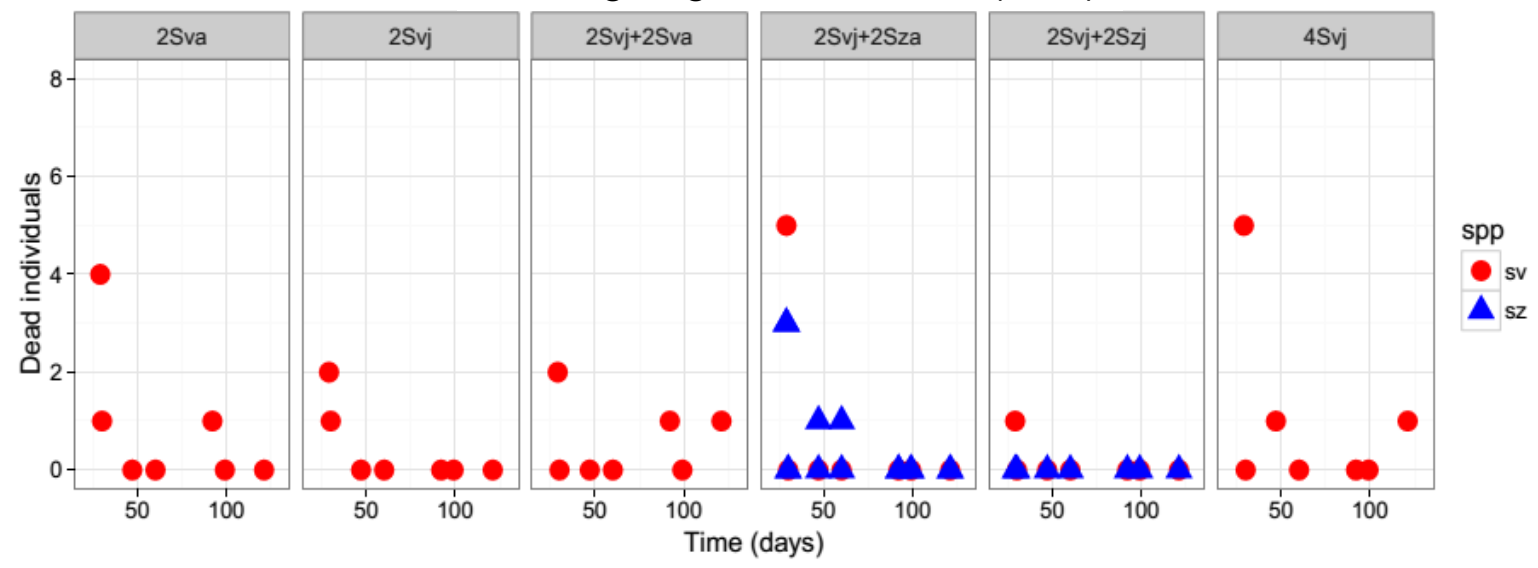

898

899 Fig. S4. Total number of dead individuals (3 replicate per treatments) found inside

900 experimental enclosures through time, in field experiments conducted at the Historic Range 901 Overlap (HRO) and at the leading edge (LE) of S. viridula. SV: Scurria viridula; SZ: S.

902 zebrina.

903

904 
a) Historic Range Overlap

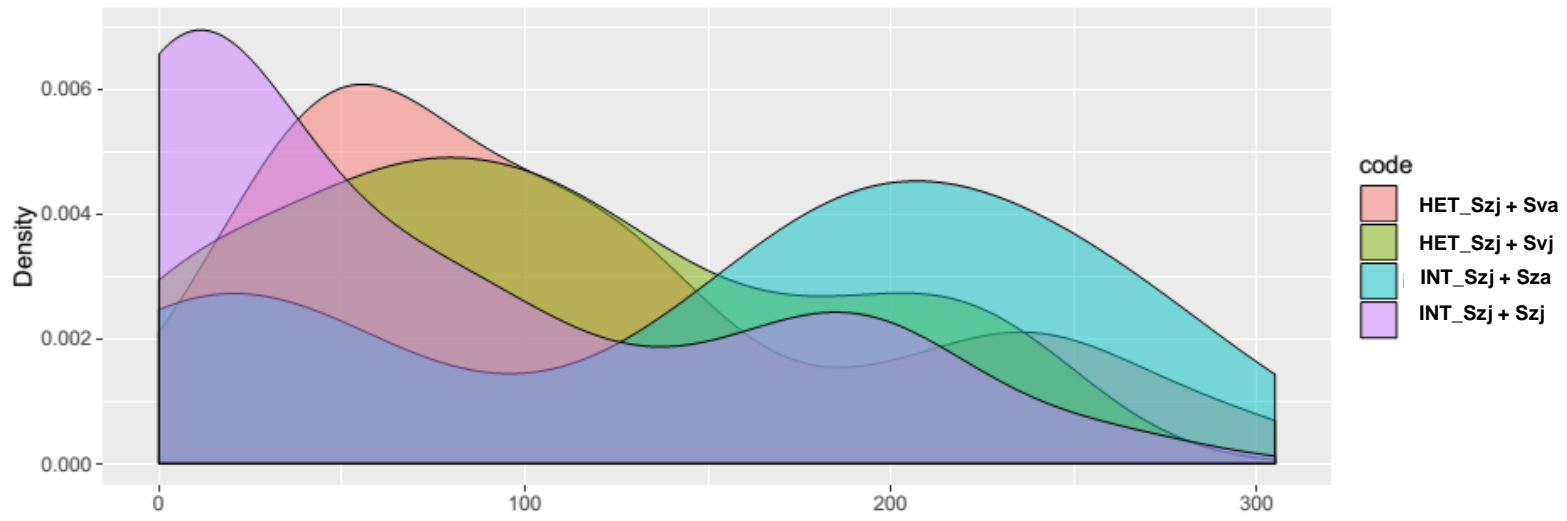

b) Leading Edge

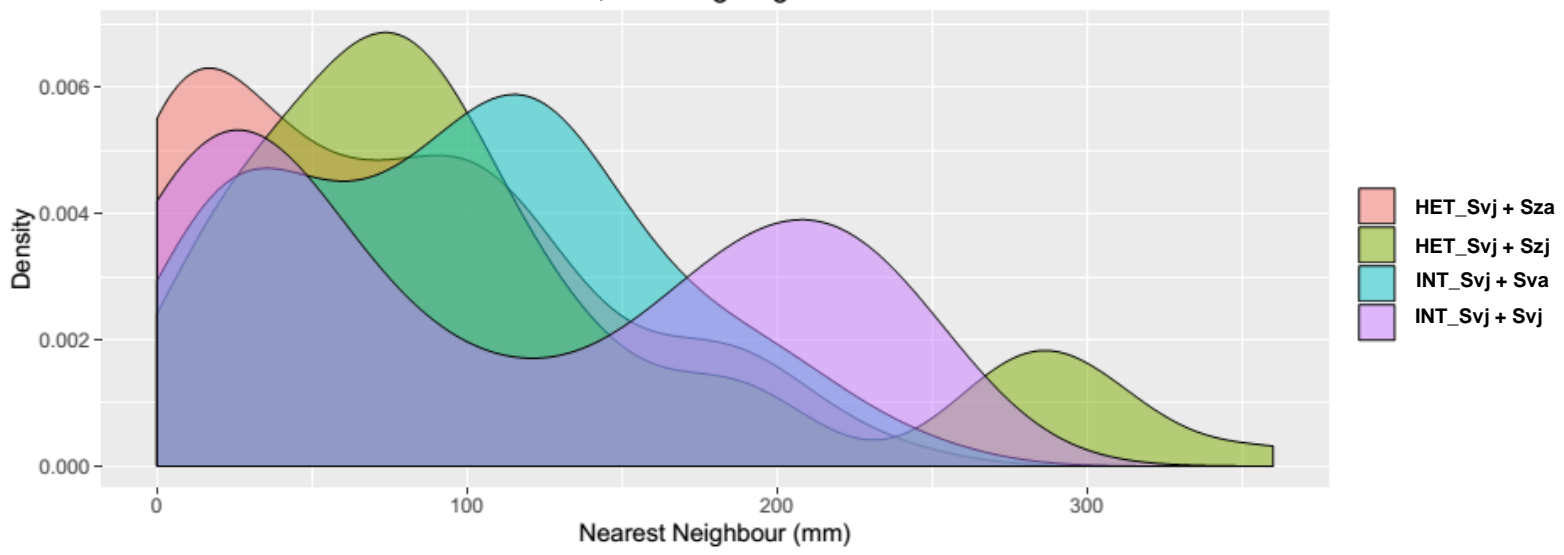

906 Fig. S5. Density plot of the intra (INT) and heterospecific (HET) individual nearest neighbor distances $(\mathrm{NN})$ estimated inside experimental plots, in experiments conducted in 908 the historic range overlap $\left(30^{\circ} \mathrm{S}\right)$ a), and at the leading edge of $S$. viridula at Las Cruces 909 (33 ${ }^{\circ}$ S) b). SZ: S. zebrina; SV: S.viridula. Subscripts "j" and "a" denote "juvenile" and 910 "adult" individuals, respectively. 


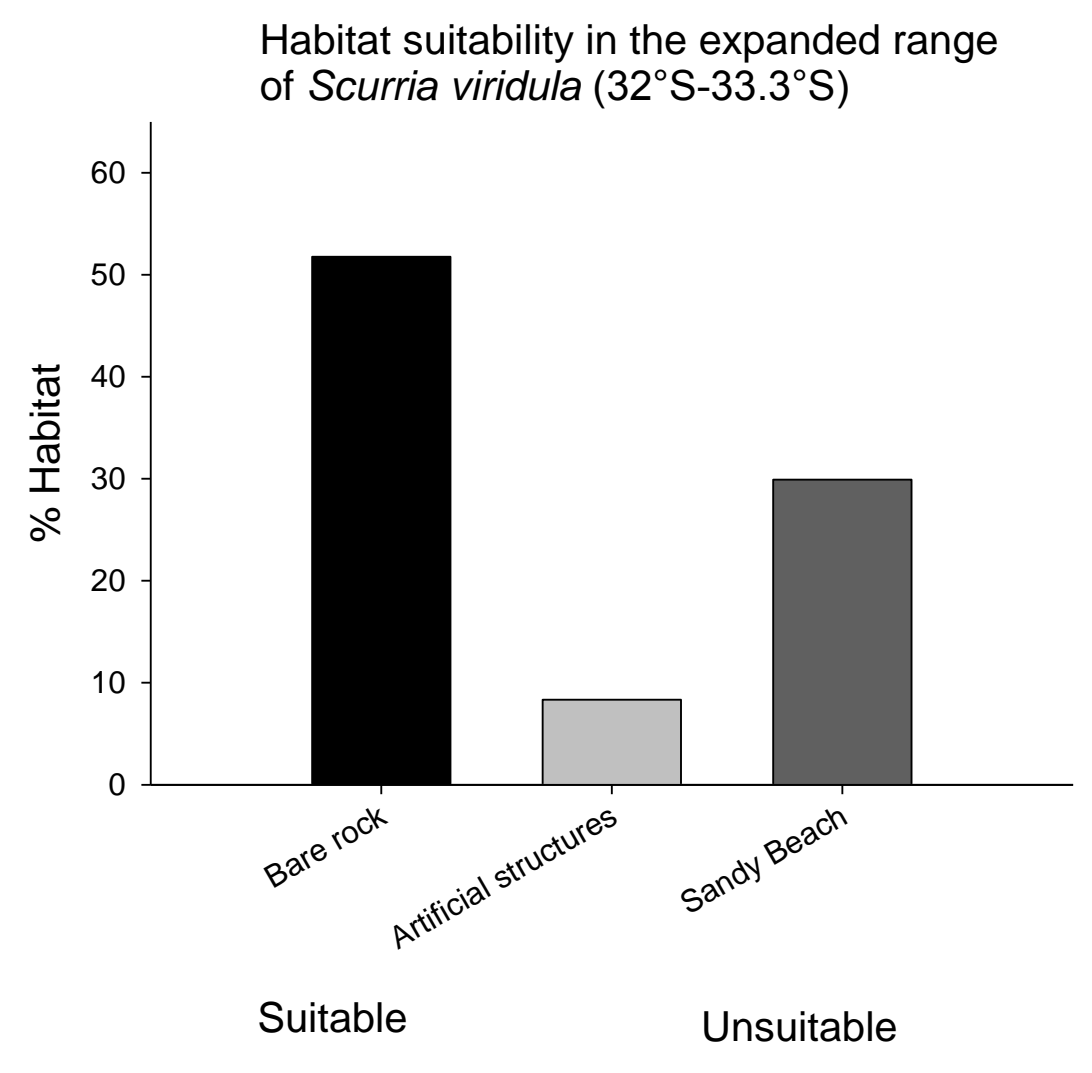

917 Fig. S6. Proportion of suitable (bare rock, artificial structures) and unsuitable (sandy beach) 918 habitat from $32^{\circ} \mathrm{S}$ to $33^{\circ} \mathrm{S}$ corresponding to the leading edge of $S$. viridula (LE). Analyses 919 were conducted through tracing contours of the coast in Google Earth at constant elevation 920 (500m) (Fenberg \& Rivadeneira 2011).

921

922

923

924

925

926

927

928

929

930 
931 Table S1. Summary of the different localities sampled during the study, and the number of 932 quadrat deployed in different transects (rocky platforms) at different year and seasons.

933 *Platform extent correspond to the entire sampled areas included in the quadrat sampling, 934 and which were also completely checked (visually) for presence of Scurria species.

935

936

\begin{tabular}{|c|c|c|c|c|c|}
\hline Locality & $\begin{array}{l}\text { Latitude } \\
\quad\left({ }^{\circ} \mathrm{S}\right)\end{array}$ & $\begin{array}{c}\text { Number of } \\
\text { quadrats } \\
\left(30^{\star} 30 \mathrm{~cm}\right)\end{array}$ & $\begin{array}{c}\text { Rocky } \\
\text { platform } \\
\text { extent }\left(m^{2}\right)^{*}\end{array}$ & Season & Year \\
\hline \multirow[t]{2}{*}{ Arica } & \multirow[t]{2}{*}{18.28} & $\begin{array}{l}25 \\
20 \\
23\end{array}$ & $\begin{array}{l}1(60) \\
2(87) \\
3(60)\end{array}$ & $\begin{array}{l}\text { Winter } \\
\text { Winter } \\
\text { Winter }\end{array}$ & $\begin{array}{l}2014 \\
2014 \\
2014\end{array}$ \\
\hline & & $\begin{array}{l}12 \\
12\end{array}$ & $\begin{array}{l}1(60) \\
2(60)\end{array}$ & $\begin{array}{l}\text { Summer } \\
\text { Summer }\end{array}$ & $\begin{array}{l}2016 \\
2016\end{array}$ \\
\hline \multirow[t]{3}{*}{ Iquique } & \multirow[t]{3}{*}{20.14} & $\begin{array}{l}12 \\
21 \\
26 \\
\end{array}$ & $\begin{array}{l}1(75) \\
2(60) \\
3(60) \\
\end{array}$ & $\begin{array}{l}\text { Summer } \\
\text { Summer } \\
\text { Summer }\end{array}$ & $\begin{array}{l}2013 \\
2013 \\
2013 \\
\end{array}$ \\
\hline & & $\begin{array}{l}20 \\
15 \\
25\end{array}$ & $\begin{array}{l}1(75) \\
2(60) \\
3(60)\end{array}$ & $\begin{array}{l}\text { Winter } \\
\text { Winter } \\
\text { Winter }\end{array}$ & $\begin{array}{l}2014 \\
2014 \\
2014 \\
\end{array}$ \\
\hline & & $\begin{array}{l}15 \\
15 \\
15 \\
\end{array}$ & $\begin{array}{l}1(75) \\
2(60) \\
3(60) \\
\end{array}$ & $\begin{array}{l}\text { Summer } \\
\text { Summer } \\
\text { Summer }\end{array}$ & $\begin{array}{l}2016 \\
2016 \\
2016 \\
\end{array}$ \\
\hline \multirow{3}{*}{ Paposo } & \multirow[t]{3}{*}{25.2} & $\begin{array}{l}15 \\
20 \\
\end{array}$ & $\begin{array}{l}1(35) \\
2(35) \\
\end{array}$ & $\begin{array}{l}\text { Summer } \\
\text { Summer }\end{array}$ & $\begin{array}{l}2014 \\
2014 \\
\end{array}$ \\
\hline & & $\begin{array}{l}20 \\
15 \\
20 \\
\end{array}$ & $\begin{array}{l}1(35) \\
2(35) \\
3(30) \\
\end{array}$ & $\begin{array}{l}\text { Winter } \\
\text { Winter } \\
\text { Winter }\end{array}$ & $\begin{array}{l}2014 \\
2014 \\
2014 \\
\end{array}$ \\
\hline & & $\begin{array}{l}15 \\
15 \\
\end{array}$ & $\begin{array}{l}1(35) \\
2(35)\end{array}$ & $\begin{array}{l}\text { Summer } \\
\text { Summer }\end{array}$ & $\begin{array}{l}2015 \\
2015 \\
\end{array}$ \\
\hline Pan de Azúcar & 26.17 & $\begin{array}{l}15 \\
10 \\
\end{array}$ & $\begin{array}{l}1(20) \\
2(20)\end{array}$ & $\begin{array}{l}\text { Winter } \\
\text { Winter }\end{array}$ & $\begin{array}{l}2014 \\
2014 \\
\end{array}$ \\
\hline \multirow{4}{*}{ Carrizal Bajo } & \multirow{4}{*}{28} & $\begin{array}{l}15 \\
25 \\
\end{array}$ & $\begin{array}{l}1(80) \\
2(24)\end{array}$ & $\begin{array}{l}\text { Spring } \\
\text { Spring }\end{array}$ & $\begin{array}{l}2013 \\
2013 \\
\end{array}$ \\
\hline & & $\begin{array}{l}20 \\
20\end{array}$ & $\begin{array}{l}1(24) \\
2(24)\end{array}$ & $\begin{array}{l}\text { Summer } \\
\text { Summer }\end{array}$ & $\begin{array}{l}2014 \\
2014\end{array}$ \\
\hline & & $\begin{array}{l}20 \\
16\end{array}$ & $\begin{array}{l}1(24) \\
2(24)\end{array}$ & $\begin{array}{l}\text { Autumn } \\
\text { Autumn }\end{array}$ & $\begin{array}{l}2014 \\
2014\end{array}$ \\
\hline & & 15 & $1(24)$ & Summer & 2015 \\
\hline \multirow[t]{4}{*}{ Los Burros } & \multirow[t]{4}{*}{28.5} & 12 & $1(43)$ & Winter & 2013 \\
\hline & & 17 & $1(43)$ & Spring & 2013 \\
\hline & & 15 & $1(43)$ & Summer & 2014 \\
\hline & & 16 & $1(43)$ & Autumn & 2014 \\
\hline
\end{tabular}




\begin{tabular}{|c|c|c|c|c|c|}
\hline \multirow{6}{*}{ Arrayán } & \multirow{6}{*}{29} & $\begin{array}{l}25 \\
26 \\
\end{array}$ & $\begin{array}{l}1(48) \\
2(80) \\
\end{array}$ & $\begin{array}{l}\text { Summer } \\
\text { Summer }\end{array}$ & $\begin{array}{l}2013 \\
2013 \\
\end{array}$ \\
\hline & & 10 & $1(48)$ & Autumn & 2013 \\
\hline & & 15 & $1(48)$ & Winter & 2013 \\
\hline & & 15 & $1(48)$ & Spring & 2013 \\
\hline & & $\begin{array}{l}18 \\
15\end{array}$ & $\begin{array}{l}1(48) \\
2(80)\end{array}$ & $\begin{array}{l}\text { Summer } \\
\text { Summer }\end{array}$ & $\begin{array}{l}2014 \\
2014\end{array}$ \\
\hline & & 15 & $1(48)$ & Winter & 2014 \\
\hline \multirow{9}{*}{ Guanaqueros } & \multirow{9}{*}{30.1} & 13 & $1(90)$ & Summer & 2013 \\
\hline & & 16 & $1(90)$ & Winter & 2013 \\
\hline & & 12 & $2(55)$ & Winter & 2013 \\
\hline & & 13 & $1(90)$ & Spring & 2013 \\
\hline & & 28 & $2(55)$ & Spring & 2013 \\
\hline & & 16 & $1(90)$ & Summer & 2014 \\
\hline & & 15 & $2(55)$ & Summer & 2014 \\
\hline & & 15 & $1(90)$ & Autumn & 2014 \\
\hline & & 15 & 1(90) & Spring & 2014 \\
\hline Limarí & 30.4 & 12 & $1(84)$ & Summer & 2015 \\
\hline \multirow{7}{*}{ Punta de Talca } & \multirow{7}{*}{30.5} & 15 & $1(120)$ & Winter & 2013 \\
\hline & & 15 & $2(128)$ & Winter & 2013 \\
\hline & & 18 & $1(120)$ & Spring & 2013 \\
\hline & & 18 & $1(120)$ & Summer & 2014 \\
\hline & & 20 & $1(120)$ & Autumn & 2014 \\
\hline & & 15 & $1(120)$ & Winter & 2014 \\
\hline & & 15 & $1(120)$ & Summer & 2015 \\
\hline \multirow{8}{*}{ Huentelauquén } & \multirow{8}{*}{31.38} & 10 & $1(80)$ & Summer & 2013 \\
\hline & & 16 & $1(80)$ & Winter & 2013 \\
\hline & & 20 & $1(80)$ & Spring & 2013 \\
\hline & & 18 & $1(80)$ & Summer & 2014 \\
\hline & & 20 & $2(48)$ & Summer & 2014 \\
\hline & & 20 & $1(80)$ & Autumn & 2014 \\
\hline & & 19 & $2(48)$ & Autumn & 2014 \\
\hline & & 25 & $1(80)$ & Summer & 2015 \\
\hline \multirow{8}{*}{ Quintay } & \multirow{8}{*}{33.11} & 20 & $1(35)$ & Summer & 2013 \\
\hline & & 20 & $2(60)$ & Summer & 2013 \\
\hline & & 20 & $1(35)$ & Spring & 2013 \\
\hline & & 20 & $2(60)$ & Spring & 2013 \\
\hline & & 21 & $1(35)$ & Winter & 2013 \\
\hline & & 15 & $2(60)$ & Winter & 2013 \\
\hline & & 20 & $1(35)$ & Summer & 2014 \\
\hline & & 15 & $1(35)$ & Winter & 2015 \\
\hline & & 21 & $1(84)$ & Summer & 2013 \\
\hline Las Cruces & 33.3 & 12 & $2(56)$ & Summer & 2013 \\
\hline
\end{tabular}




\begin{tabular}{|c|c|c|c|c|c|}
\hline & & 13 & $3(45)$ & Summer & 2013 \\
\hline & & $\begin{array}{l}12 \\
12\end{array}$ & $\begin{array}{l}1(84) \\
2(56)\end{array}$ & $\begin{array}{l}\text { Winter } \\
\text { Winter }\end{array}$ & $\begin{array}{l}2013 \\
2013\end{array}$ \\
\hline & & 15 & $1(84)$ & Summer & 2014 \\
\hline & & $\frac{12}{15}$ & $\begin{array}{l}2(56) \\
1(84)\end{array}$ & Summer & $\frac{2014}{2014}$ \\
\hline & & 15 & $1(84)$ & Winter & 2014 \\
\hline & & 13 & $2(56)$ & Winter & 2014 \\
\hline & & 15 & $1(84)$ & Winter & 2015 \\
\hline & & 16 & $1(84)$ & Summer & 2016 \\
\hline & & 15 & $2(56)$ & Summer & 2016 \\
\hline & & 30 & $1(120)$ & Summer & 2013 \\
\hline & & 15 & $2(100)$ & Summer & 2013 \\
\hline Pelancura & 33.33 & 25 & $1(120)$ & Winter & 2013 \\
\hline & & 24 & $2(100)$ & Winter & 2013 \\
\hline & & 30 & $1(120)$ & Summer & 2014 \\
\hline & & 27 & $1(120)$ & Autumn & 2014 \\
\hline & & 20 & $1(120)$ & Summer & 2015 \\
\hline & & 15 & $1(78)$ & Winter & 2014 \\
\hline Matanzas & 33.57 & 15 & $2(65)$ & Winter & 2014 \\
\hline & & 15 & $3(42)$ & Winter & 2014 \\
\hline & & 25 & $1(425)$ & Winter & 2014 \\
\hline Pichilemu & 34.25 & 25 & $2(234)$ & Winter & 2014 \\
\hline & & 25 & $3(513)$ & Winter & 2014 \\
\hline Cocholgüe & 36.35 & 30 & $1(125)$ & Autumn & 2014 \\
\hline Desembocadura & 36.6 & 27 & $1(40)$ & Autumn & 2014 \\
\hline Colcura & 37.11 & 30 & $1(40)$ & Autumn & 2014 \\
\hline Punta Ronca & 39.39 & 36 & $1(45)$ & Autumn & 2014 \\
\hline Cheuque & 39.4 & 15 & $1(78)$ & Summer & 2014 \\
\hline Calfuco & 39.79 & 30 & $1(80)$ & Summer & 2014 \\
\hline Chaihuin & 39.94 & 30 & $1(46)$ & Autumn & 2014 \\
\hline Pucatrihue & 40.53 & 44 & $1(84)$ & Autumn & 2014 \\
\hline Puñihuil & 41.92 & 34 & $1(34)$ & Summer & 2014 \\
\hline
\end{tabular}

937

938

939

940

941

942

943 
946 Table S2. Pearson's spatial correlation (r) between Scurria species abundances estimated in 947 the field through a quadrat $(30 \times 30 \mathrm{~cm})$ sampling protocol. Significance $(\alpha=0.05)$ was

948 calculated through a t-test, corrected for the effective degrees of freedom based on lag-1 949 autocorrelation estimates of Moran's I (Dutilleul 1993).

950

951

952

953

954

955

956

957

\begin{tabular}{|l|c|}
\hline \multicolumn{1}{|c|}{ Site } & $\begin{array}{l}\text { Pearson's r } \\
\text { P-value }\end{array}$ \\
\hline Guanaqueros & -0.0388 \\
$\left(30.12^{\circ}\right.$ S; HRO) & 0.3907 \\
\hline Punta Talca & 0.0323 \\
$\left(30.55^{\circ} \mathrm{S}\right.$; HRO) & 0.7397 \\
\hline Huentelauquén & 0.0223 \\
$\left(31.38^{\circ} \mathrm{S} ;\right.$ HRO) & $\mathbf{0 . 0 1 4 5}$ \\
\hline Quintay & -0.0741 \\
$\left(33.11^{\circ} \mathrm{S}\right.$; LE) & 0.0803 \\
\hline
\end{tabular}

958

959

960

961

962

963

964

965

966

967

968

969

970

971

972 
974 Table S3. Average percent cover $( \pm$ SE) of the main algal groups observed inside

975 experimental enclosures at the end of the field experiments. Ephemerals: Ulva compressa, $976 U$. rigida, Scytosiphon lomentaria and Bangia sp., Periphyton: Microalgae (diatoms,

977 cyanophytes), Crustose algae: Hildenbrandia lecanelleri, Ralfsia sp.

978

\begin{tabular}{cccc}
\hline $\begin{array}{c}\text { Leading edge of } \\
\text { Scurria viridula (LE) }\end{array}$ & & & \\
\hline Treatment & Ephemeral & Periphyton & Crustose algae \\
\hline & & & \\
$2 S v j+2 S z j$ & $76.25 \pm 4.27$ & $10.75 \pm 5.37$ & $3.25 \pm 1.18$ \\
$2 S v j+2 S z a$ & $32.5 \pm 7.5$ & $25.75 \pm 18.27$ & $7.0 \pm 27.1$ \\
$2 S v j+2 S v a$ & $16.25 \pm 14.01$ & $8.25 \pm 0.5$ & $40 \pm 3.14$ \\
$2 S v j$ & $71.75 \pm 14.0$ & $3.5 \pm 0.5$ & $6.25 \pm 3.14$ \\
$4 S v j$ & $25.0 \pm 18.92$ & $7.5 \pm 2.5$ & $13.5 \pm 10.5$ \\
$2 S v a$ & $33.25 \pm 16.42$ & $2.25 \pm 0.75$ & $42.0 \pm 21.94$
\end{tabular}

$\begin{array}{cccc}2 S z j+2 S v j & 16.15 \pm 6.88 & 1.5 \pm 0.866 & 0 \\ 2 S z j+2 S v a & 3.75 \pm 3.75 & 1.25 \pm 1.25 & 0 \\ 2 S z j+2 S z a & 20 \pm 12.47 & 0.75 \pm 0.75 & 1.5 \pm 1.0 \\ 2 S z j & 53.75 \pm 12.5 & 0.75 \pm 0.74 & 0 \\ 4 S z j & 28.33 \pm 0.13 & 0 & 0 \\ 2 S z a & 10 \pm 5.77 & 1.2 \pm 1.0 & 0\end{array}$

981 


\section{Appendix S1. Nearest neighbor distance distribution analyses}

The NN distances measured in the field surveys were analyzed by generating contingency tables of the proportion of individuals that had specific NN distances (e.g. ranging from 0.0 to $89.0 \mathrm{~cm}$ ). Independence of $\mathrm{NN}$ across the different localities was tested with the likelihood ratio test and Pearson's chi-square. For these analyses, reflexive NN distances

994 (i.e. when 2 individuals are mutually nearest neighbors; Cox, 1981) were not considered.

995 Because con- and heterospecific NN-distances estimated in the experimental enclosures in

996 field experiments include non-independent measures (same individuals sampled through 997 time) and small sample size, they were analyzed differently; we estimated the probability 998 density function (PDF) for conspecific and heterospecific NN distance distribution in each experimental plot. Thus, considering that NN-distances are continuous random variables, the PDF (i.e. kernel density plot) was estimated as the ratio of individual NN distances

1001 values versus the average total. This non-parametric estimation utilizes a kernel smoothing 1002 (in this case Gaussian) to plot values, allowing for comparison of smoother distributions, 1003 and providing a useful way to explore individual segregation or aggregation (Manly, 1997).

1004 Density plots were performed with the package 'sm' implemented in R (R Development 1005 Core Team, 2017). territorial and gregarious intertidal grazers: consequences for individual behaviour. PLoS ONE, 7(9), e46205. doi:10.1371/journal.pone.0046205 
1011

1012

1013

1014

1015

1016

1017

1018

1019

1020

1021

1022

1023

1024

1025

1026

1027

1028

1029

1030

1031

1032

1033

1034

1035
Aguilera, M. A., Valdivia, N., \& Broitman, B. R. (2013). Spatial niche differentiation and coexistence at the edge: co-occurrence distribution patterns in Scurria limpets. Marine Ecology Progress Series, 483, 185-198. doi:10.3354/meps 10293

Cox, T. F. (1981). Reflexive Nearest Neighbours. International Biometric, 37(2), 367-369.

Manly, B. (1997). Randomization, Bootstrap and MonteCarlo Methods in Biology (p. 388). Chapman \& Hall.

R Development Core Team. (2017). R: a language and environment for statistical computing. R Foundation for Statistical Computing, Vienna, Austria. (R. F. for S. Computing, Ed.). Vienna. Retrieved from URL http://www.R-project.org/.

\section{Appendix 2. Field experiments: main protocols}

\section{Field experiments design and set up}

To examine the effect of $S$. viridula on $S$. zebrina juvenile individuals at the historic range overlap $\left(30^{\circ} \mathrm{S}\right)$, we established treatments examining both intraspecific effects of $S$. zebrina (juvenile-juvenile, adult-adult and juvenile-adult interactions) and interspecific effects (juveniles of each species and juveniles of $S$. zebrina interacting with adults of $S$ viridula) (see Fig. 1 in the main text). To examine the effect of $S$. zebrina on $S$. viridula juvenile individuals in the leading edge of the latter species $\left(33.3^{\circ} \mathrm{S}\right)$, we deployed the three treatments (see information provided in the main text) to examine intraspecific effects, but in this case on $S$. viridula, and both treatments designed to examine interspecific effects (i.e. juveniles of each species and $S$. zebrina adult-S. viridula juvenile). In both sites, 
intraspecific effects were investigated at either natural or high densities (two or four

1037 individuals per plot, respectively; see Table 1 and Fig. 1 in the main text), and interspecific

1038 effects were examined using natural densities of each species (two individuals of each

1039 species).

1040 Experimental treatment considered at each site; Historic range overlap (HRO): $\underline{\text { Intraspecific }}$

1041 effects: 1) 2 S. zebrina juveniles; 2) 4 S. zebrina juveniles; 3) 2 S. zebrina adults; 4) $2 S$.

1042 zebrina juveniles plus 2 S. zebrina adults (inter-size effect). Interspecific effects: 5) $2 S$.

1043 zebrina juveniles plus 2 S. viridula juveniles, and 6) 2 S. zebrina juveniles plus 2 S. virdula

1044 adults; Leading edge (LE): 1) 2 S. viridula juveniles; 2) 4 S. viridula juveniles; 3) $2 S$.

1045 viridula adults; 4) 2 S. viridula juveniles plus 2 S. viridula adults, 5) 2 S. viridula juveniles

1046 plus 2 S. zebrina juveniles, and 6) 2 S. viridula juveniles plus 2 S. zebrina adults.

1047 Treatments were randomly allocated to experimental areas and replicated four times. Mixed

1048 species treatment at high densities were not considered (see Table 1 in the main text), due

1049 to the reduced densities of $S$. viridula at the leading edge, and to avoid artefacts caused by

1050 large individuals enclosed in small areas. Scurria individuals were enclosed in

1051 experimental areas $(35 \times 35 \mathrm{~cm})$ using stainless steel mesh cages $(8 \mathrm{~cm}$ high, $10 \mathrm{~mm}$ mesh

1052 size) fastened to the rock with stainless steel screws. Gaps between the substratum and the

1053 base of the fences were sealed with plastic mesh. Any losses/mortality after the formal start

1054 of the experiment in Punta Talca and Las Cruces were attributed to competition (e.g.

1055 individual contests or food shortage). To control for the potential impact of cages (e.g. light

1056 reduction, water flow), 12 S. viridula and 12 S. zebrina juvenile individuals were tagged,

1057 measured and left in the same place with no cage. Survival and activity patterns of these

1058 individuals were checked twice per month. This procedural control was conducted at both 
1059

1060

1061

1062

1063

1064

1065

1066

1067

1068

1069

1070

1071

1072

1073 Appendix S3

1074

1075

1076

1077

1078

1079

1080

1081

1082

sites. All Scurria individuals were collected in the same intertidal zone (mid-high intertidal

level $\sim 2.0$ MLWL) where the experiments were performed, and where both species inhabit

(Aguilera, Valdivia, \& Broitman, 2013), the experimental plot and collection sites were

distanced $\sim 3-4$ meters apart. At the start of the experiments each organism was weighted

(wet), sized and labelled with a bee tag before deployment into the experimental

enclosures. Previous studies showed the foraging range of Scurria species encompass a

radius of $\sim 12-18 \mathrm{~cm}$ around their home scar (Aguilera et al. unpublished). For both species,

the discrimination between juvenile and adults was based on readily visible morphological

differences (see Aguilera et al., 2013) corroborated by observations of first sexual maturity

of both species occurring in individuals of $35 \mathrm{~mm}$ in shell length. Average shell length of

juveniles for each species used in the experiments was $23.5 \pm 0.1 \mathrm{~mm}$ (wet weight $=2.1 \pm$

$0.04 \mathrm{~g})$; average shell length of adults was $50.5 \pm 0.7 \mathrm{~mm}(20.6 \pm 0.7 \mathrm{~g}$; Table 1$)$.

\section{Interaction strength measures for field experiments}

In order to provide estimates of interaction strength between species and between size classes for each species in experimental treatments (described above and in the main text), we estimated per capita intra- and interspecific effects as follow (see also Aguilera \& Navarrete, 2012): For a given species $i$ (S. viridula and S. zebrina in their respective range edges) and size class $k$ (i.e. juvenile, adult), the per capita intraspecific effects (ISi) were

calculated as: $I S_{i_{k}}=\frac{\left(R H i_{k}-R N i_{k}\right)}{\left(N H i_{k}-N N i_{k}\right)}$, where $R N i_{k}$ is the per capita response variable (e.g. growth rate) of species $i$ of size class $k$ (juvenile or adult) in the average or "natural", 
1083 density treatment, $R H i_{k}$ is the per capita response measured in the high density treatment, 1084 and $N N i_{k}$ and $N H i_{k}$ are the numbers of individuals in the average and high density 1085 treatments, respectively. Thus for each location we estimated three intraspecific effects; 1086 juvenile on juvenile $\left(I S i_{j j}\right)$, adult on juvenile $\left(I S i_{a j}\right)$, and juvenile on adult $\left(I S i_{j a}\right)$. The total 1087 per capita interspecific effect (Total_ISij) of species $\mathrm{j}$ on species $i$ was then calculated as:

1088 Total_IS $i_{j_{k}}=\frac{\left(R M i j_{k}-R N i_{k}\right)}{N j_{k}}$, where $R M i j_{k}$ is the per capita response of species $i$ measured in 1089 the mixed species enclosures with species $j$ of size class $k$, and $N j_{k}$ is the number of 1090 individuals of species $j$ of class $k$ present in those enclosures. Per capita interspecific 1091 effects do not separate between "pure" per capita effects due to addition of a different 1092 species (identity effect), from the expected changes observed if individuals of the same 1093 species, but of different size class, were added to the arena (intraspecific effects) (Aguilera 1094 \& Navarrete, 2012). Therefore, considering that per capita intraspecific effects would 1095 maintain constant (and linear over the density range and size class considered) in the 1096 presence of heterospecifics, we obtained an estimate of "pure" per capita ISijk as;

$1097 I S i j_{k}=$ Total_ISij $j_{k}-I S i_{k}$. Confidence intervals for estimates of per capita interaction 1098 strengths were obtained through bootstrapping our observations 1000 times (Manly, 1997).

1099 We then evaluated whether the $95 \%$ bootstrapped confidence intervals overlapped zero to 1100 judge if the particular effect was statistically significant. All analyses were conducted in the 1101 R environment v. 3.1.3 (R Development Core Team, 2017). territorial and gregarious intertidal grazers: consequences for individual behaviour. PLoS ONE, 7(9), e46205. doi:10.1371/journal.pone.0046205 
1107

1108

1109

1110

1111

1112

1113

1114

1115

1116

1117

1118
Aguilera, M. A., Valdivia, N., \& Broitman, B. R. (2013). Spatial niche differentiation and coexistence at the edge: co-occurrence distribution patterns in Scurria limpets. Marine Ecology Progress Series, 483, 185-198. doi:10.3354/meps10293

Cox, T. F. (1981). Reflexive Nearest Neighbours. International Biometric, 37(2), 367-369.

Manly, B. (1997). Randomization, Bootstrap and MonteCarlo Methods in Biology (p. 388). Chapman \& Hall.

R Development Core Team. (2017). R: a language and environment for statistical computing. R Foundation for Statistical Computing, Vienna, Austria. (R. F. for S. Computing, Ed.). Vienna. Retrieved from URL http://www.R-project.org/. 